\title{
Análisis del funcionamiento espacial del municipio de Florencia - Caquetá
}

\section{Hugo Hernando Rincón López*}

Resumen. En el presente artículo se expone parte de los resultados del trabajo de investigación denominado "Organización Espacial y Funcional del Municipio de Florencia, Caquetá", realizado por el autor para optar el título de Magíster en Geo grafía con énfasis en Ordenamiento Territorial. Sustentado teórica y metodológicamente en la "teoría de los lugares centrales" y en el "enfoque de las funciones urbanas para el desarrollo rural", se efectuó el análisis funcional municipal teniendo como unidad básica el "Centro poblado" y partiendo de la premisa de que cada centro por pequeño que sea, ofrece una gama de servicios básicos a la población concentrada y a la población dispersa de su área de influencia; lo cual ha generado un sistema de fun cionamiento espacial municipal en el que Florencia constituye el centro de gravedad mayor subsidiado por pequeños centros distribuidos aleatoriamente por todo el territorio municipal, jerarquizados funcionalmente de acuerdo a su tamaño, número de funciones y centralidad.

Palabras clave: funcionamiento espacial, análisis morfológico, tipología funcional, jerarquía urbana, vínculos e interacciones espaciales, unidades de funcionamiento espacial.

(Aceptado noviembre 2002).

\footnotetext{
* Profesor Asociado de la Universidad de la Amazonia. Magíster en Geografía con énfasis en Ordenamiento Territorial. Especialista en Alternativas de Desarrollo Sostenible para la Amazonia Colombiana. Geógrafo Profesional. Licenciado en Ciencias Sociales.
} 


\section{Introducción}

La organización y el funcionamiento espacial del municipio de Florencia se ha venido construyendo a través del tiempo teniendo como nodo la ciudad de Florencia, que debido a su hipercefalia a nivel municipal y departamental por el excesivo peso demográfico, económico, político y administrativo, ha generado marcados desequilibrios territoriales que se reflejan en el bajo nivel de desarrollo de los demás asentamientos humanos del municipio. Para determinar el sistema de relaciones funcionales establecido entre Florencia y la red de asentamientos intramunicipales, se escogió como unidad de análisis espacial los dieciocho centros poblados ${ }^{1}$ presentes en el municipio, buscando evidenciar sus niveles de articulación e integración a través de la delimitación de "unidades de funcionamiento espacial" que permitieran evaluar su actual organización territorial para conocer si es adecuada para el desarrollo integral y sostenible del municipio.

Esta investigación se fundamenta teórica y metodológicamente en algunos modelos y enfoques utilizados por la disciplina geográfica en el análisis espacial, tales como la "Teoría de los Lugares Centrales", el "Enfoque de las
Funciones Urbanas para el Desarrollo Rural" y el "Análisis Locacional", en el contexto del Ordenamiento Territorial colombiano.

Además de los aportes que se presentan en materia de la organización y del funcionamiento espacial del municipio de Florencia, los cuales podrán, en el futuro, ser integrados al Plan de Ordenamiento Territorial, considero que uno de los avances más significativos de esta investigación a nivel geográfico, fue la de aplicar una metodología para el análisis del funcionamiento espacial a un territorio, donde no existe un sistema consolidado de centros urbanos y que, por el contrario, los asentamientos presentan un tamaño poblacional muy reducido.

\section{Análisis urbano-municipal}

\subsection{Análisis del sistema de asentamientos}

El análisis del sistema de asentamientos del municipio de Florencia comprende la identificación de los Centros Poblados Rurales (ver mapa 1) y sus áreas de influencia, dentro del territorio municipal y fuera de él, para determinar las interrelaciones tanto internas como externas. Este análisis busca determinar la ubicación de la

\footnotetext{
1 Según el Censo Nacional de Población y vivienda de 1993 levantado por el DANE, los centros poblados se definieron como "concentraciones de edificaciones correspondientes a 20 o más viviendas contiguas o con una conformación de características urbanas, es decir, manzanas, calles y carreras".
}

58 Hugo Hernando Rincón López 
población y clasificar los centros poblados del municipio de acuerdo a las siguientes variables:

- Determinación de la distribución de los centros poblados rurales.

- Clasificación morfológica: para identificar y diferenciar los asentamientos urbanos y rurales con base en el tamaño de la población y sus características físicas.

- Clasificación por tamaño de población: para categorizar los asentamientos de acuerdo con el número de habitantes.

- Clasificación funcional: para diferenciar los centros poblados según sus actividades económicas y sociales, $\mathrm{y}$ determinar su jerarquía funcional.

Según el enfoque FUDR -Funciones Urbanas para el Desarrollo Rural(Rondinelli, 1988, 142) el análisis del sistema de asentamientos se "centra en las características funcionales de las comunidades y describe una región como un patrón de asentamientos humanos definido por características tanto de población como funcionales". Por tanto, este análisis permite:

- "Identificar los distintos elementos o componentes del sistema de asentamientos, esto es, el número y localización de comunidades en las cuales las gentes viven e interactúan entre sí, desem-peñando importantes actividades económicas".
- "Determinar las características funcionales de las comunidades y el grado en el cual los asentamientos sirven a la población asentada fuera de sus límites, esto es, el grado en el que los asenta-mientos en el sistema son lugares centrales".

- "Delinear el patrón de asentamientos dentro de la región, esto es, sus niveles de jerarquía y de difusión y la centralidad de lugares dentro de ella".

\subsubsection{Distribución espacial de los centros poblados}

"Los asentamientos se pueden disponer sobre el espacio de formas muy distintas. En algunos casos tienden a concentrarse en ciertas áreas que, por determinadas circunstancias, ofrecen buenas posibilidades para la vida del hombre, pero en otros casos los asentamientos tienden a dispersarse de forma más o menos regular por todo el territorio" (del canto Fresno, Consuelo, 1993, 201). Uno de los métodos utilizados más frecuentemente para medir la distribución de los asentamientos en el espacio geográfico es el índice $R_{n}$, que se expresa como:

$\mathrm{R}_{\mathrm{n}}=2 \mathrm{~d} \sqrt{ } \mathrm{N} / \mathrm{S}$, donde $\mathrm{d}$ es la distancia media de cada asentamiento respecto al más próximo en un territorio de superficie $\mathrm{S}$, en el existen $\mathrm{N}$, número de asentamientos. El valor del índice $R_{n}$, puede oscilar entre 0 y 2,15 . 
Cuando el índice es igual a 0 indica una distribución totalmente concentrada ${ }^{2}$; el valor de 2,15 señalaría la existencia de un sistema de asentamientos en el que dispersión sería máxima ${ }^{3}$; el caso intermedio entre la concentración absoluta y la dispersión uniforme es una distribución aleatoria ${ }^{4}$ y ocurre cuando los valores se acercan a 1 .
Para el cálculo de este índice se incluye a Florencia, por cuanto aquí se trata de determinar la distribución espacial del sistema de asentamientos humanos del municipio (ver cuadro 1).

Para calcular d se obtiene la distancia promedio entre los núcleos más próximos, así:

Cuadro 1

Cálculo del índice $\mathbf{R}_{\mathbf{n}}$ en el municipio de Florencia

\begin{tabular}{|l|l|c|}
\hline \multicolumn{1}{|c|}{ CENTROS POBLADOS } & \multicolumn{1}{|c|}{$\begin{array}{c}\text { CENTRO POBLADO } \\
\text { MÁS PRÓXIMO }\end{array}$} & $\begin{array}{c}\text { DINTANCIA } \\
(\mathbf{k m})\end{array}$ \\
\hline FLORENCIA & SEBASTOPOL & 3,0 \\
\hline CAPITOLIO & FLORENCIA & 6,4 \\
\hline VENECIA & PUERTO ARANGO & 1,2 \\
\hline PUERTO ARANGO & VENECIA & 1,2 \\
\hline REMOLINO ORTEGUAZA & SAN GUILLERMO & 9,0 \\
\hline SAN GUILLERMO & REMOLINO ORTEGUAZA & 9,0 \\
\hline SEBASTOPOL & LA PRIMAVERA & 0,9 \\
\hline NUEVA JERUSALÉN & LA PRIMAVERA & 0,9 \\
\hline AVENIDA EL CARAÑO & VILLARAZ & 2,2 \\
\hline LA PRIMAVERA & NUEVA JERSALÉN & 0,9 \\
\hline VILLARAZ & AVENIDA EL CARAÑO & 2,2 \\
\hline MARACAIBO & PUERTP ARANGO & 9,2 \\
\hline NORCASIA & LA ESPERANZA & 11,0 \\
\hline EL PARÁ & REMOLINO ORTEGUAZA & 9,9 \\
\hline VILLA HERMOSA & BAJO SAN GIL & 8,4 \\
\hline BAJO SAN GIL & VILLA HERMOSA8 & 8,4 \\
\hline SAN ANTONIO DE ATENAS & SANTANA LAS HERMOSAS & 5,7 \\
\hline SANTANA LAS HERMOSAS & LA ESPERANZA & 4,7 \\
\hline LA ESPERANZA & SANTANA LAS HERMOSAS & 4,7 \\
\hline TOTALES & CAPITAL + 18 CENTROS POBLADOS & $\mathbf{9 8 , 9}$ \\
\hline
\end{tabular}

Fuente: Esta investigación.

2 Todos los asentamientos se concentrarían tanto en una misma zona que estarían prácticamente tocándose.

3 Todos los asentamientos se distribuirían uniformemente por el espacio, ninguno estaría cercano al otro y la distancia entre cada uno y el más próxima sería la mayor posible.

4 Al azar, sin ningún tipo de orden. 
$\mathrm{d}=98,9 / 19 \quad \mathrm{~d}=5,2 \mathrm{~km}$

Aplicando la fórmula, tenemos:

$\mathrm{R}_{\mathrm{n}}=2 \mathrm{~d} \sqrt{ } \mathrm{N} / \mathrm{S}$

$\mathrm{R}_{\mathrm{n}}=2 \times 5,2 \sqrt{ } 19 / 2.403,9$

$\mathrm{R}_{\mathrm{n}}=0,92$

El índice de distribución espacial de los asentamientos es igual a 0,92 , es decir, se aproxima a 1, lo cual significa que, la distribución espacial de los centros poblados, incluyendo la ciudad capital, del municipio de Florencia es de tipo aleatorio, con una cierta tendencia hacia la concentración; es decir, que aunque se encuentren distribuidos por todo el territorio de forma no regular existe la tendencia de concentrarse en la zona de cordillera.

De hecho los centros tienden a localizarse en el paisaje montañoso donde hay mayor densidad de población debido a las características del relieve, al tipo de actividad agrícola que se realiza y a la alta fragmentación de la tierra, a diferencia de la parte baja y plana del municipio donde predomina la ganadería extensiva con un régimen de mediana y gran propiedad.

\subsubsection{Análisis morfológico}

Además de la capital municipal que al mismo tiempo es la capital departamental, en el municipio de
Florencia existe un sistema de asentamientos humanos distribuidos en siete Corregimientos con dieciocho centros poblados, que de acuerdo a sus características morfo-lógicas (red vial, servicios públicos, transporte público, equipamientos, continuidad en las edificaciones, materiales de construcción, espacios públicos, etc.), demográficas (total de población concentrada), socieconómicas (actividades desempeñadas ${ }^{5}$ ) y bajo nivel de urbanización se les considera como Centros Poblados Rurales. Por tanto, solamente la ciudad de Florencia se le puede considerar como un asentamiento urbano mientras que los dieciocho Centros Poblados son asentamientos rurales (ver cuadro 2).

Estos asentamientos se encuentran localizados sobre las carreteras municipales que facilitan su interconección con la ciudad de Florencia, a excepción de San Guillermo que en lugar de Florencia está interconectado con la ciudad de Garzón (departamento del Huila) a través de una vía directa San Guillermo - Garzón.

El único centro que no está conectado a ninguna cabecera municipal (dentro o fuera del departamento) través de una vía carreteable es Remolino Orteguaza, cuyos niveles de accesibilidad son muy bajos. Los asentamientos ubicados a menos de treinta minutos de Florencia,

5 La mayor parte de su población depende de la economía rural, por tanto, la ocupación de la mayoría de sus habitantes es en actividades agropecuarias; no obstante haya asentamientos muy cercanos a Florencia, lo cual hace que algunas personas trabajen en actividades urbanas en esta ciudad. 
tales como Avenida El Caraño, Capitolio, Sebastopol, Venecia, Nueva Jerusalén, Puerto Arango y La Primavera presentan mayor accesibilidad a la capital y algunos de sus habitantes laboran en esta ciudad.

\subsubsection{Tamaño de la población}

El total de población concentrada en el municipio es de 116.520 habitantes, de los cuales el $96,14 \%$ vive en Florencia, único asentamiento del municipio que se considera urbano. Es decir, que sólo el $3,86 \%$ de la población vive concentrada en Centros Poblados Rurales. Aquí se observa con toda intensidad la "macrocefalia" de la capital frente al resto de asentamientos humanos; lo que permite colegir que existe un enorme desequilibrio poblacional entre los centros poblados y la ciudad Capital, la cual deja muy poca oportunidad para que los centros poblados se desarrollen.

\section{Cuadro 2}

Asentamientos urbanos y rurales del municipio de Florencia

\begin{tabular}{|l|r|r|c|}
\hline \multicolumn{1}{|c|}{ CENTRO POBLADO } & $\begin{array}{c}\text { TOTAL } \\
\text { POBLACIÓN } \\
\text { (Año 2000) }\end{array}$ & $\begin{array}{c}\text { \% DE } \\
\text { POBLACIÓN } \\
\text { CONCENTRADA }\end{array}$ & $\begin{array}{c}\text { TIPO DE } \\
\text { ASENTAMIIENTO }\end{array}$ \\
\hline FLORENCIA & 112.019 & 96,14 & URBANO \\
\hline NUEVA JERUSALÉN & 585 & 0,50 & RURAL \\
\hline NORCASIA & 553 & 0,47 & RURAL \\
\hline EL PARÁ & 476 & 0,41 & RURAL \\
\hline PUERTO ARANGO & 381 & 0,33 & RURAL \\
\hline AVENIDA EL CARANO & 358 & 0,31 & RURAL \\
\hline LA PRIMAVERA & 321 & 0,28 & RURAL \\
\hline SANTANA LAS HERMOSAS & 262 & 0,22 & RURAL \\
\hline LA ESPERANZA & 261 & 0,22 & RURAL \\
\hline SEBASTOPOL & 256 & 0,22 & RURAL \\
\hline SAN ANTONIO DE ATENAS & 234 & 0,20 & RURAL \\
\hline VENECIA & 143 & 0,12 & RURAL \\
\hline SAN GUILLERMO & 134 & 0,12 & RURAL \\
\hline REMOLINO ORTEGUAZA & 122 & 0,10 & RURAL \\
\hline MARACAIBO & 112 & 0,10 & RURAL \\
\hline CAPITOLIO & 109 & 0,09 & RURAL \\
\hline BAJO SAN GIL & 83 & 0,07 & RURAL \\
\hline VILLA HERMOSA & 69 & 0,06 & RURAL \\
\hline VILLARAZ & 42 & 0,04 & RURAL \\
\hline TOTAL POBLACIÓN CONCENTRADA & $\mathbf{1 1 6 . 5 2 0}$ & $\mathbf{1 0 0}$ & \\
\hline
\end{tabular}

Fuente: Secretaría de Planeación Municipal. 
No obstante, si analizamos el sistema de asentamientos humanos del municipio sin tener en cuenta la capital, aplicando el índice de primacía (Ip) para los cuatro centros con mayor población, tenemos:

$$
\mathrm{Ip}=\frac{\mathrm{P}_{1}}{\mathrm{P}_{1}+\mathrm{P}_{2}+\mathrm{P}_{3}+\mathrm{P}_{4}} \mathrm{x} 100
$$

$$
\text { Ip } \underset{585+555+475+380}{585} \text { × } 100 \quad \text { Ip }=29
$$

El índice de primacía ${ }^{6}$ relativamente bajo indica que el sistema de asentamientos rurales del municipio (sin tener en cuenta a Florencia) presenta un modelo policéntrico, donde no hay un asentamiento que concentre la mayor parte de la población, sino por el contrario, los cuatro centros con más población tienen un número similar de habitantes.

Los 18 Centros Poblados Rurales constituyen pequeños polos de atracción que concentran algunas funciones mínimas básicas (servicios), los cuales conforman un área de influencia cuya extensión y alcance varía según el tamaño, la distancia y facilidades de acceso.
Para efectos de clasificar de los centros poblados por tamaño se establecen los siguientes grupos (intervalos de clase $)^{7}$ y se le asigna una categoría, siendo 1 para el mayor y así sucesivamente de mayor a menor; luego se pondera teniendo en cuenta la categoría, así: categoría $1=3$, categoría $2=2$, categoría $3=1$.

Los centros poblados tienen un tamaño relativamente pequeño, pues solo existen tres centros en el municipio con población superior a 405 habitantes; siete, entre 224 - 404 y ocho, con menos de 223 habitantes (ver cuadro anterior).

\subsection{Tipología funcional de los centros poblados rurales}

\subsubsection{Características funcionales}

Las características funcionales del sistema de centros poblados rurales del municipio de Florencia, están representadas por el número y diversidad de funciones básicas o servicios que ofrecen estos asentamientos, lo cual permite establecer la centralidad de cada uno de ellos, variable clave en la determinación del grado de jerarquía funcional de los centros poblados.

\footnotetext{
6 Mediante el índice de primacía se compara el tamaño del centro poblado mayor (Nueva Jerusalén) con el de los tres centros siguientes (Norcasia, El Pará y Puerto Arango). Este índice expresa el porcentaje que representa la población del centro poblado mayor del municipio con respecto a la suma de las poblaciones de los cuatro mayores (incluido él mismo). Sus valores extremos pueden oscilar entre 100 (macrocefalia) y 25 (policentrismo). En primer caso, toda la población se concentraría en un solo centro; en el segundo caso, los cuatro mayores centros tendrían exactamente el mismo número de habitantes.

7 Para determinar los grupos se utilizó la distribución de frecuencias con datos agrupados.
} 
Grupos

Grupo 1: $\quad 405-585$

Grupo 2: $\quad 224-404$

Grupo 3: $\quad 42-223$

\section{Frecuencias}

3

7

8

Cuadro 3

Tamaño de los centros poblados rurales

\begin{tabular}{|c|c|c|c|}
\hline GRUPOS & CENTROS POBLADOS & CATEGORÍA & PONDERACIÓN \\
\hline \multirow[t]{3}{*}{$1: 405-585$} & Nueva Jerusalén & 1 & 3 \\
\hline & Norcasia & 1 & 3 \\
\hline & El Pará & 1 & 3 \\
\hline \multirow[t]{7}{*}{$2: 224-404$} & Puerto Arango & 2 & 2 \\
\hline & Avenida El Caraño & 2 & 2 \\
\hline & La Primavera & 2 & 2 \\
\hline & Santana Las Hermosas & 2 & 2 \\
\hline & La Esperanza & 2 & 2 \\
\hline & Sebastopol & 2 & 2 \\
\hline & San Antonio de Atenas & 2 & 2 \\
\hline \multirow[t]{8}{*}{$3: 42-223$} & Venecia & 3 & 1 \\
\hline & San Guillermo & 3 & 1 \\
\hline & Remolino Orteguaza & 3 & 1 \\
\hline & Maracaibo & 3 & 1 \\
\hline & Capitolio & 3 & 1 \\
\hline & Bajo San Gil & 3 & 1 \\
\hline & Villa Hermosa & 3 & 1 \\
\hline & Villaraz & 3 & 1 \\
\hline
\end{tabular}

Fuente: Esta investigación.

Estos centros deben su existencia a la concentración de población rural en un espacio relativamente reducido donde se mezclan algunos usos de carácter urbano con usos rurales, pero todos o la mayor parte de los habitantes dependen de la actividad agropecuaria. El conjunto de funciones o servicios prestados es el que determina la jerarquía del centro.
Aunque la base económica de estos centros dependa totalmente de las actividades agropecuarias, existen algunas funciones relacionadas con actividades de intercambio de bienes y servicios que representan una importante fuente de ingresos $y$ ocupación de sus habitantes. Estas actividades se reflejan en la comercialización de alimentos y

64 Hugo Hernando Rincón López 
bebidas, acopio y venta de insumos agropecuarios, servicios públicos, sociales y de transporte, los cuales son redistribuidos a sus áreas de influencia inmediata.

\subsubsection{Clasificación funcional}

Para la clasificación funcional de los centros poblados se utiliza el método del escalograma que permite determinar el número y diversidad de funciones de todos y cada uno de los centros poblados del sistema de asentamientos del municipio de Florencia. Según el IGAC $(2000,31)$, "la clasificación funcional pretende diferenciar los asentamientos con base en los tipos, combinaciones y diversidad de las actividades económicas y sociales localizadas en ellos"(ver escalograma de funciones o servicios ofrecidos por todos y cada uno de los dieciocho centros poblados del municipio de Florencia).

El sistema de asentamientos de centros poblados rurales del municipio de Florencia se clasifica teniendo en cuenta el número de funciones básicas (de mayor a menor) con que cuenta cada centro de la siguiente manera (ver escalograma):

$\begin{array}{lcc}\text { Niveles } & \text { Grupos } & \text { Frecuencias } \\ \text { PRIMER NIVEL: } & 10-12 & 5 \\ \text { SEGUNDO NIVEL: } & 07-09 & 5 \\ \text { TERCER NIVEL: } & 03-06 & 8\end{array}$

Con base en estos intervalos de clase de las funciones y agrupando en ellos a los Centros Poblados por niveles, se determina la siguiente clasificación:

\section{Cuadro 4}

Niveles de clasificación funcional de los centros poblados

\begin{tabular}{|c|c|c|}
\hline $\begin{array}{c}\text { NIVELES } \\
\text { JERÁRQUICOS }\end{array}$ & \multicolumn{1}{c|}{ CENTROS POBLADOS } & PONDERACIÓN \\
\hline PRIMERNIVEL & $\begin{array}{l}\text { El Pará, Remolino Orteguaza, Norcasia, } \\
\text { San Guillermo, Santana Las Hermosas }\end{array}$ & 3 \\
SEGUNDONIVEL & $\begin{array}{l}\text { Puerto Arango, San Antonio de Atenas, } \\
\text { Maracaibo, La Esperanza, Villa Hermosa }\end{array}$ & 2 \\
TERCERNIVEL & $\begin{array}{l}\text { Nueva Jerusalén, La Primavera, Venecia, } \\
\text { Sebastopol, Avenida El Caraño, Villaraz, } \\
\text { Bajo San Gil, Capitolio }\end{array}$ & 1 \\
\hline
\end{tabular}

Fuente: Esta investigación. 


\section{Escalograma de funciones básicas o servicios ofrecidos por los Centros Poblados}

\begin{tabular}{|c|c|c|c|c|c|c|c|c|c|c|c|c|c|c|c|c|c|c|c|c|c|}
\hline $\begin{array}{l}\text { FU N CIONES } \\
\text { CENTROS POBLADOS }\end{array}$ & 1 & 2 & 3 & 4 & 5 & 6 & 7 & 8 & 9 & 10 & 11 & 12 & 13 & 14 & 15 & 16 & 17 & 18 & 19 & 20 & $\begin{array}{l}\text { TO- } \\
\text { TAL }\end{array}$ \\
\hline CAPITOLIO & $\mathrm{X}$ & & & & & & & & & $\mathrm{X}$ & $\mathrm{X}$ & & & & & & & $\mathrm{X}$ & & & 4 \\
\hline VENECIA & $\mathrm{X}$ & & & & $\mathrm{X}$ & & & & & $\mathrm{X}$ & $\mathrm{X}$ & & & & & & & & & & 4 \\
\hline PUERTO ARANGO & $\mathrm{X}$ & & & $\mathrm{X}$ & & & $\mathrm{X}$ & & $\mathrm{X}$ & $\mathrm{X}$ & $\mathrm{X}$ & & $\mathrm{X}$ & & $\mathrm{X}$ & & $\mathrm{X}$ & & & & 9 \\
\hline REMOLINO ORTEGUAZA & $\mathrm{X}$ & & $\mathrm{X}$ & & $\mathrm{X}$ & $\mathrm{X}$ & $\mathrm{X}$ & $\mathrm{X}$ & $\mathrm{X}$ & $\mathrm{X}$ & & $\mathrm{X}$ & & $\mathrm{X}$ & & & & & $\mathrm{X}$ & & 11 \\
\hline SAN GUILLERMO & $\mathrm{X}$ & & $\mathrm{X}$ & & $\mathrm{X}$ & $\mathrm{X}$ & & & $\mathrm{X}$ & $\mathrm{X}$ & $\mathrm{X}$ & $\mathrm{X}$ & $\mathrm{X}$ & $\mathrm{X}$ & $\mathrm{X}$ & & & & & & 11 \\
\hline AVENIDA EL CARAÑO & & & $\mathrm{X}$ & & & & $\mathrm{X}$ & & & $\mathrm{X}$ & $\mathrm{X}$ & & & & & & & & & & 4 \\
\hline LA PRIMAVERA & $\mathrm{X}$ & & & & & & & & & $\mathrm{X}$ & $\mathrm{X}$ & & & & & $\mathrm{X}$ & $\mathrm{X}$ & & & & 5 \\
\hline VILLARAZ & $\mathrm{X}$ & & & & & & & & & $\mathrm{X}$ & $\mathrm{X}$ & & & & & & & & & & 3 \\
\hline MARACAIBO & $\mathrm{X}$ & & $\mathrm{X}$ & $\mathrm{X}$ & & & & & $\mathrm{X}$ & $\mathrm{X}$ & $\mathrm{X}$ & $\mathrm{X}$ & & & & & & & & & 7 \\
\hline NORCASIA & $\mathrm{X}$ & $\mathrm{X}$ & $\mathrm{X}$ & $\mathrm{X}$ & $\mathrm{X}$ & $\mathrm{X}$ & $\mathrm{X}$ & & $\mathrm{X}$ & $\mathrm{X}$ & $\mathrm{X}$ & & & & $\mathrm{X}$ & & & & & & 11 \\
\hline S.TANA LAS HERMOSAS & $\mathrm{X}$ & $\mathrm{X}$ & $\mathrm{X}$ & $\mathrm{X}$ & $\mathrm{X}$ & $\mathrm{X}$ & $\mathrm{X}$ & & & $\mathrm{X}$ & $\mathrm{X}$ & & & & $\mathrm{X}$ & & & & & & 10 \\
\hline LA ESPERANZA & $\mathrm{X}$ & & $\mathrm{X}$ & $\mathrm{X}$ & $\mathrm{X}$ & & & & & $\mathrm{X}$ & $\mathrm{X}$ & & & $\mathrm{X}$ & & & & & & $\mathrm{X}$ & 8 \\
\hline TOTAL FUNCIONES & 16 & 2 & 12 & 6 & 9 & 6 & 5 & 1 & 9 & 18 & 17 & 5 & 3 & 3 & 6 & 1 & 3 & 1 & 2 & 2 & 127 \\
\hline
\end{tabular}

Fuente: Esta investigación.

1. Escuela
2. Colegio
3. Puesto de salud
4. TELECOM (SAI)
5. Templo religioso

1. Escuela

5 . Templo religioso

6. Cementerio

7. Oficina Corregidor

8. Plaza de mercado

9. Matadero

10. Tiendas (misceláneas)
11. Transporte público

12. Salón comunal

13. Cooperativas

14. Polideportivo

15. Cancha de fútbol
16. Estación de servicios

17. Talleres

18. Fabricas

19. Parque central

20. SENA 
Algunos centros localizados cerca de la ciudad de Florencia (Avenida El Caraño: $15 \mathrm{~km}$, Nueva Jerusalén: 7 $\mathrm{km}$, La Primavera; 6,5 km y Sebastopol; $6 \mathrm{~km}$ ), a pesar de contar con tamaños de población que los ubican en la primera y segunda categorías, ocupan el tercer nivel de jerarquía funcional (correspondiente a Centros rurales básicos). Esta situación se debe a su proximidad con Florencia, ciudad que proporciona la mayor parte de las demandas de bienes y servicios a estas comunidades. Para el caso de Nueva Jerusalén que es el centro más poblado del municipio, este es un asentamiento de una comunidad religiosa muy compenetrada con la naturaleza y por esta razón, algunos equipamientos, servicios y actividades no están presentes allí.

Todo lo contrario sucede con los Centros Poblados más alejados de la capital (El Pará: 59,480 km, Norcasia: 48, 980 km, San Guillermo: sin vía, y Remolino Orteguaza: sin vía). Estos asentamientos cordilleranos debido a su distancia con la capital y al mal estado de las vías o por carecer de ellas, han tenido que, de alguna manera, tratar de autoabastecerse a través de la construcción de equipamientos y oferta de algunos bienes y servicios comunitarios y privados que permitan ofrecer algún bienestar a su comunidad, tanto a la concentrada en el caserío como a la dispersa en sus áreas de influencia, logrando un mayor nivel de desarrollo que los asentamientos más cercanos a Florencia. Los casos más típicos son Remolino Orteguaza que presenta aislamiento total, y San Guillermo que tiene una vía carreteable (en mal estado) que lo conecta con la ciudad de Garzón en el departamento del Huila, los cuales están totalmente desarticulados de la cabecera municipal. De esta manera, se puede afirmar que los Centros Poblados del municipio de Florencia en condiciones de aislamiento y mayor distancia de la capital municipal, que actúa como centro polarizador de su territorio, han tenido que desarrollar un mayor número de funciones para atender a una población con pocas posibilidades de seleccionar sus lugares de adquisición de bienes y servicios.

La secuencia en la cual los centros poblados acumulan funciones se puede observar en el cuadro siguiente, en el cual se relacionan las funciones de cada centro con la distancia a la capital.

Existen algunas funciones que se repiten con mayor frecuencia, es decir, presentan mayor ubicuidad ${ }^{8}$ (ver cuadro 5: escalograma) en los centros poblados, así: Tiendas (misceláneas), están presentes en todos los dieciocho centros; transporte público, en diecisiete

\footnotetext{
${ }^{8}$ Frecuencia de la presencia de funciones en los Centros Poblados.
} 


\section{Cuadro 6}

Funciones básicas de los Centros Poblados y distancia a Florencia

\begin{tabular}{|l|c|c|}
\hline \multicolumn{1}{|c|}{ CENTRO POBLADO } & $\begin{array}{c}\text { NÚMERO DE } \\
\text { FUNCIONES }\end{array}$ & $\begin{array}{c}\text { DISTANCIA } \\
\text { A FLORENCIA } \\
\text { (kms de vía) }\end{array}$ \\
\hline EL PARÁ & 12 & 59,48 \\
\hline NORCASIA & 12 & 48,98 \\
\hline REMOLINO ORTEGUAZA & 11 & No hay vía \\
\hline SAN GUILLERMO & 11 & No hay vía \\
\hline SANTANA LAS HERMOSAS & 10 & 23,17 \\
\hline PUERTO ARANGO & 09 & 15,70 \\
\hline LA ESPERANZA & 08 & 38,67 \\
\hline SAN ANTONIO DE ATENAS & 07 & 13,90 \\
\hline MARACAIBO & 07 & 31,65 \\
\hline VILLA HERMOSA & 07 & 20,10 \\
\hline NUEVAJERUSALÉN & 06 & 7,00 \\
\hline LA PRIMAVERA & 05 & 6,50 \\
\hline VENECIA & 04 & 6,00 \\
\hline SEBASTOPOL & 04 & 24,80 \\
\hline BAJO SAN GIL & 04 & 7,00 \\
\hline CAPITOLIO & 04 & 15,00 \\
\hline AVENIDA EL CARAÑ & 04 & 21,00 \\
\hline VILLARAZ & 03 & \\
\hline
\end{tabular}

Fuente: Instituto Municipal de Obras Civiles - IMOC y Esta investigación.

(falta en uno); escuelas dieciseis (falta en dos); puestos de salud, en doce (falta en seis); las funciones más escasas (menor ubicuidad), son: Talleres, fábricas y plaza de mercado, con presencia en solo un centro; parque central, colegio y SENA, en dos.

El nivel de ubicuidad permite a las autoridades municipales tomar decisiones frente a las funciones de menor frecuencia en los centros poblados, con el fin de analizar su pertinencia y implantación, ya que algunas de estas funciones son importantes para la promoción del desarrollo local, para ello es fundamental establecer el umbral ${ }^{9}$ de cada función.

9 Para Marshall, citado por Rondinelli (1988), el umbral "es aquel tamaño de centro que divide la lista ordenada de centros de tal forma que el número de centros que carecen de la función, ubicados por encima de la división, es igual al número de centros que poseen la función, ubicados por debajo de la división".

68 Hugo Hernando Rincón López 


\subsubsection{Relación entre Tamaño poblacional y número de funciones}

En el cuadro y figura siguientes se puede apreciar la relación entre el tamaño poblacional y el número de funciones básicas de cada uno de los centros poblados. En ellos se puede observar que existen tres tipos relaciones. Una relación directa, donde centros con mayor población contienen un alto número de funciones, es el caso de Norcasia, El Pará y Puerto Arango, este tipo de relación es el que supone debe esperarse ya que a mayor población mayor demanda de servicios; una relación inversa, donde centros con mayor población albergan un bajo número de funciones, corresponde a Nueva Jerusalén, Avenida El Caraño, La Primavera, Sebastopol y Capitolio, estos son los centros más cercanos a Florencia, ciudad que ofrece a todos sus habitantes una variedad de servicios y equipamientos para satisfacer la demanda sin necesidad de contar con ellos directamente, y una relación inversa, donde centros con menor población contienen un alto número de funciones, es el caso de San Guillermo, Remolino Orteguaza y

\section{Cuadro 7}

Relación tamaño poblacional - número de funciones básicas de los Centros Poblados

\begin{tabular}{|c|c|c|}
\hline CENTRO POBLADO & POBLACIÓN & $\begin{array}{l}\text { NÚMERO DE } \\
\text { FUNCIONES }\end{array}$ \\
\hline NUEVA JERUSALÉN & 585 & 06 \\
\hline NORCASIA & 553 & 12 \\
\hline EL PARÁ & 476 & 12 \\
\hline PUERTO ARANGO & 381 & 09 \\
\hline AVENIDA EL CARAÑO & 358 & 04 \\
\hline LA PRIMAVERA & 321 & 05 \\
\hline SANTANA LAS HERMOSAS & 262 & 10 \\
\hline LA ESPERANZA & 261 & 08 \\
\hline SEBASTOPOL & 256 & 04 \\
\hline SAN ANTONIO DE ATENAS & 234 & 07 \\
\hline VENECIA & 143 & 04 \\
\hline SAN GUILLERMO & 134 & 11 \\
\hline REMOLINO ORTEGUAZA & 122 & 11 \\
\hline MARACAIBO & 112 & 07 \\
\hline CAPITOLIO & 109 & 04 \\
\hline BAJO SAN GIL & 83 & 04 \\
\hline VILLA HERMOSA & 69 & 07 \\
\hline VILLARAZ & 42 & 03 \\
\hline
\end{tabular}

Fuente: Instituto Municipal de Obras Civiles - IMOC y Esta investigación. 
Villa Hermosa, asentamientos alejados de la capital y con dificultad de accesibilidad a los servicios ofrecidos por ésta, razón que ha motivado a las distintas administraciones del municipio a dotarlos de servicios y equipamientos a fin de satisfacer las necesidades más urgentes de la población concentrada y a la de sus áreas de influencia ya que son centros ubicados en frentes de colonización que es necesario consolidarlos.

\subsubsection{Análisis de umbrales de funciones}

El análisis de umbrales permite ver los tamaños de población requeridos para mantener aquellas funciones que ya existen en los Centros Poblados y para promover funciones en aquellos centros que estén por encima de los umbrales de funciones específicas que no poseen.

Siguiendo el procedimiento referenciado por Rondinelli (1988, 170) los pasos utilizados para determinar los umbrales son los siguientes:

- Lista ordenada de los centros e acuerdo con la población y la presencia (1) o ausencia (0) de cada función en cada uno de los centros.

- Aplicar la regla de Marshall e identificar el umbral de población de cada función.

- Eliminar funciones descartadas mediante la aplicación de la regla complementaria de Marshall, que plantea: "una vez que el umbral ha sido determinado, este umbral (y la función a la cual se aplica) será subsecuentemente descartado, a no ser que por lo menos la mitad de todos los centros por encima del tamaño umbral posean la función en cuestión".

Al aplicar la regla complementaria de Marshall para eliminar funciones descartadas se encuentra que la mayor parte de las funciones son eliminadas quedando solamente las siguientes funciones: escuela, tiendas (misceláneas) y transporte público, las cuales están presentes en casi todos los centros poblados, lo cual indica que estos servicios presentan buena sostenibilidad en todos los centros donde se localizan y, por tanto, requieren su mantenimiento, mejoramiento y ampliación. 


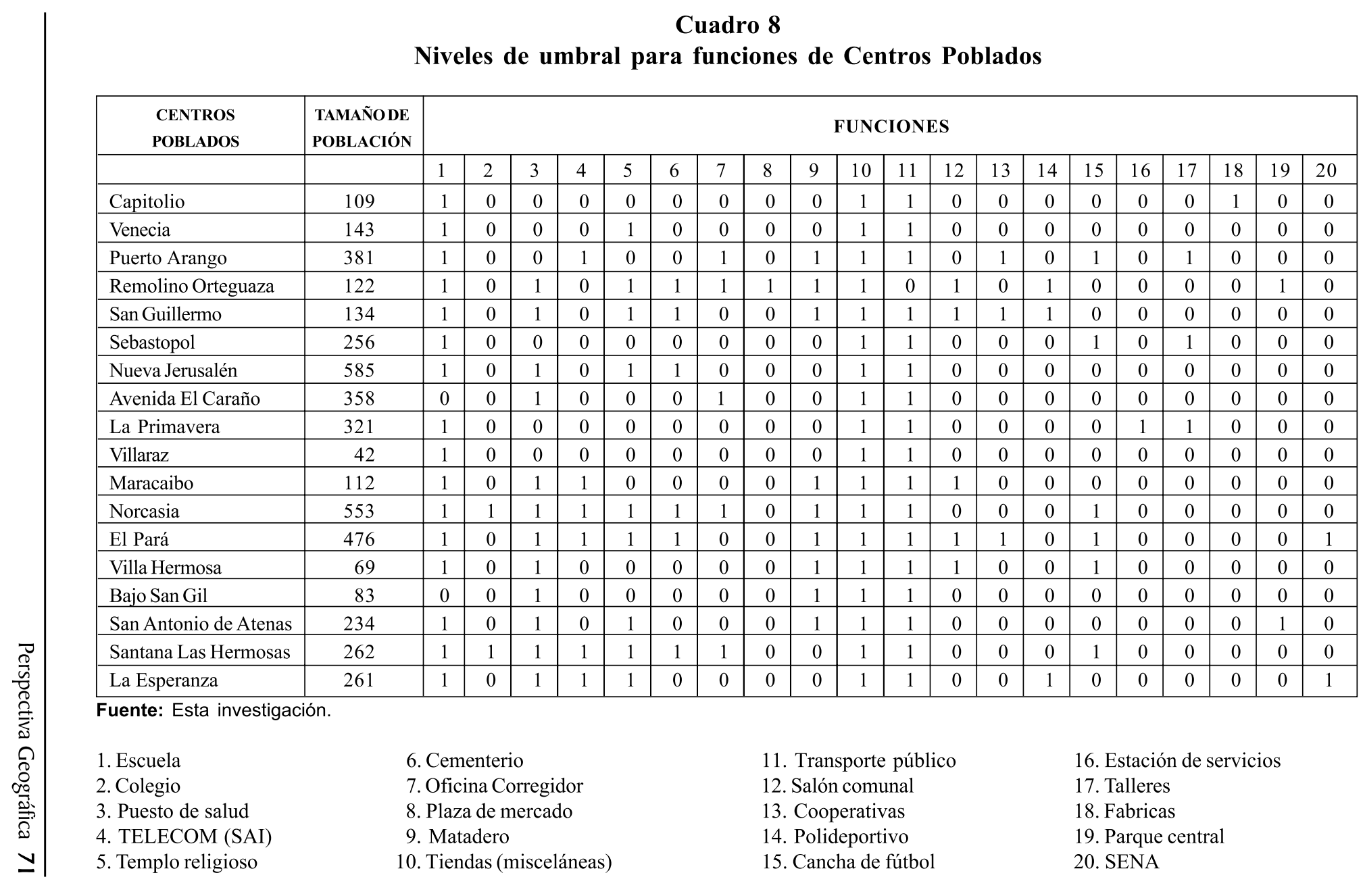


Cuadro 9 . Peso de las funciones de cada Centro Poblado

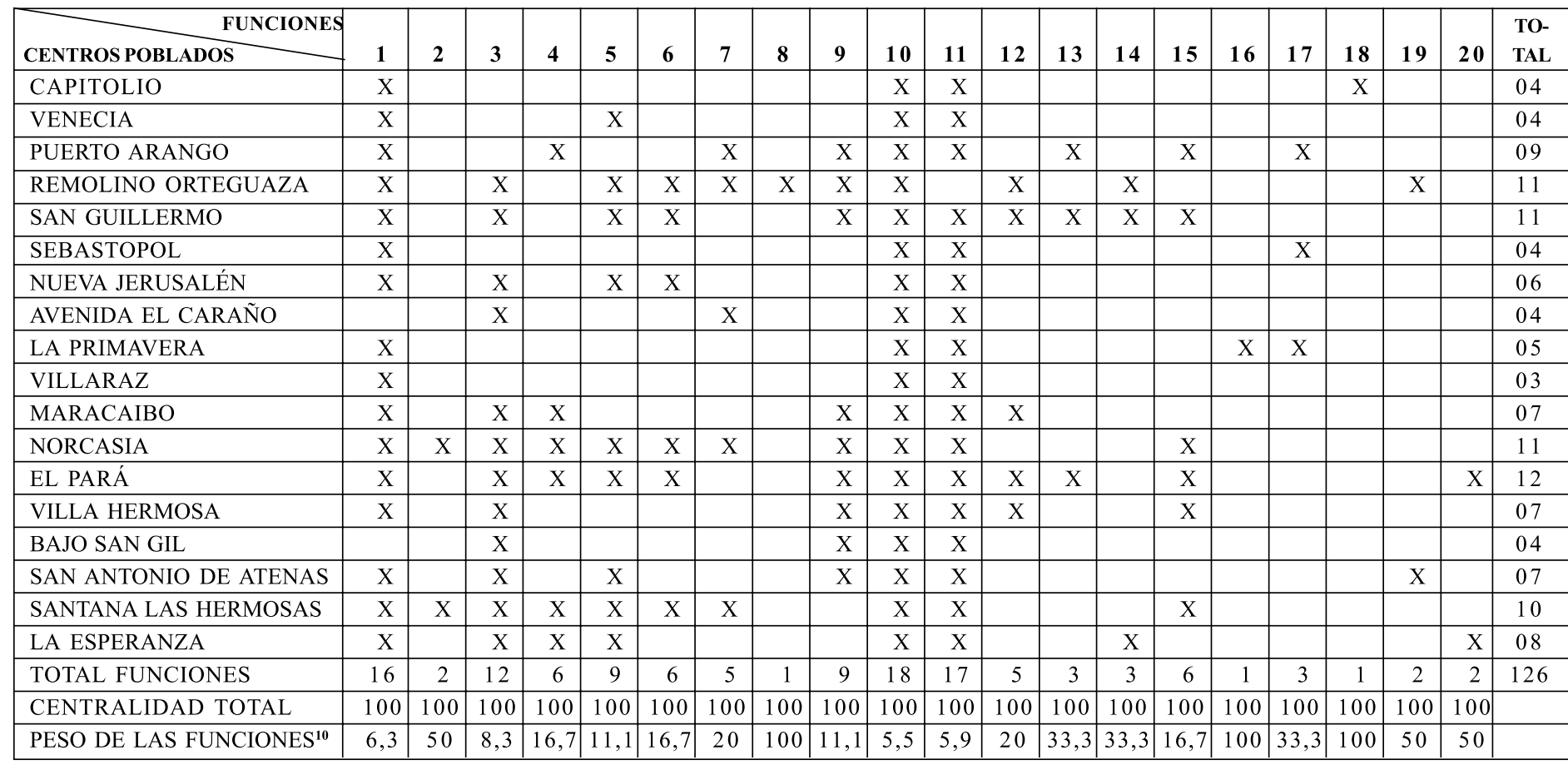

Fuente: Esta investigación.
1. Escuela
6. Cementerio
7. Oficina Corregidor
11. Transporte público
16. Estación de servicios
2. Colegio
8. Plaza de mercado
17. Talleres
4. TELECOM (SAI)
9. Matadero
13. Cooperativas
18. Fabricas
5. Templo religioso
10. Tiendas (misceláneas)
15. Cancha de
19. Parque central

${ }_{10}$ Para determinar el peso o coeficiente de localización de los atributos funcionales, se aplica la fórmula: $C=100 / T$; donde $C$ es el coeficiente de localización de la función considerada (peso del atributo funcional) y T el total de la función considerada en el sistema de Centros Poblados del municipio. 


\section{Cuadro 10}

Índice de centralidad para cada Centro Poblado

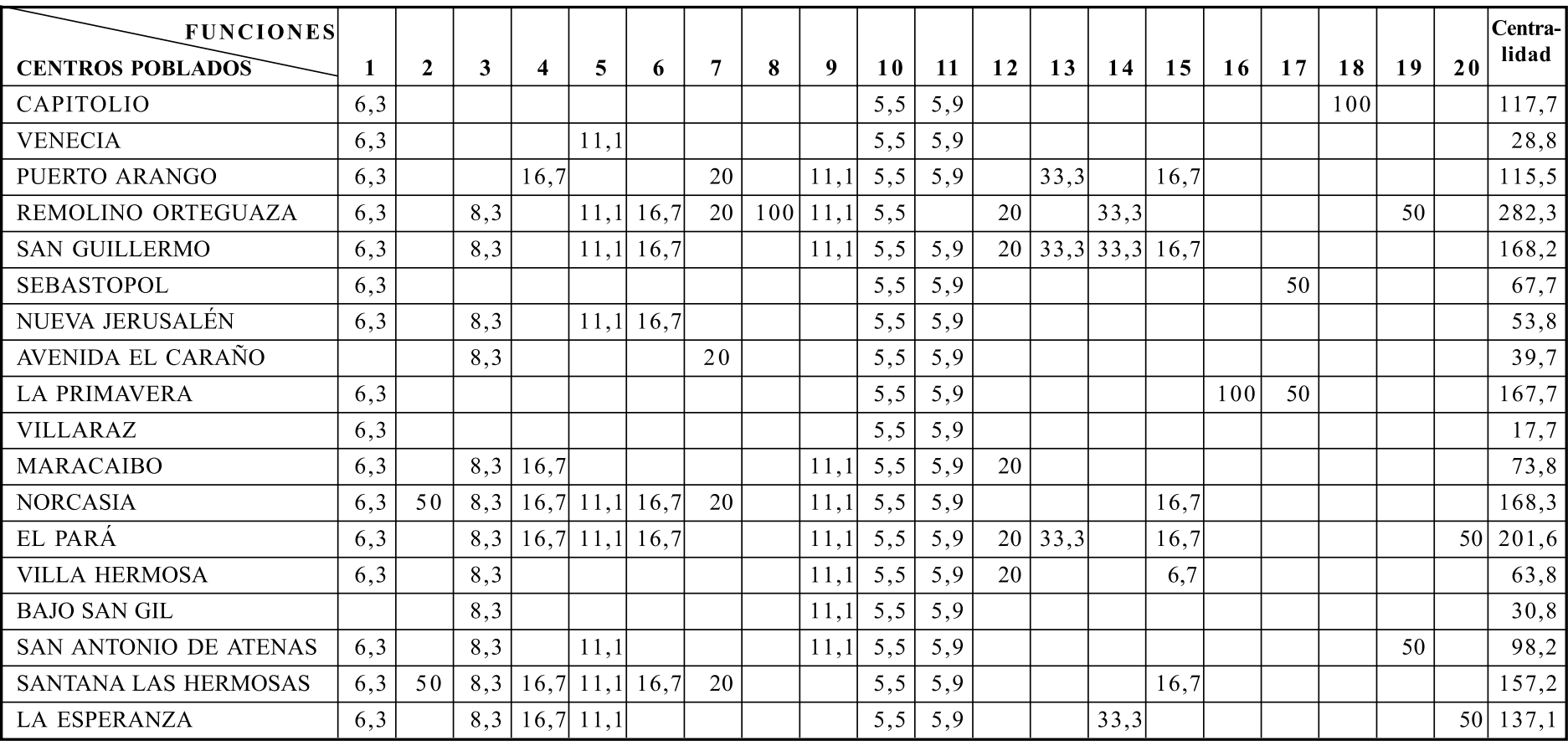

Fuente: Esta investigación.
1. Escuela
2. Colegio
3. Puesto de salud
4. TELECOM (SAI)

5. Templo religioso
6. Cementerio

7. Oficina Corregidor

8. Plaza de mercado

9. Matadero

10. Tiendas (misceláneas)
11. Transporte público

12. Salón comunal

13. Cooperativas

14. Polideportivo

15. Cancha de fútbol
16. Estación de servicios

17. Talleres

18. Fabricas

19. Parque central

20. SENA 
Los umbrales de funciones tales como, colegio, puesto de salud, telecom, templo religioso, cementerio, plaza de mercado, matadero, salón comunal, cooperativas, polideportivo y cancha de fútbol, sugieren el desarrollo de programas y proyectos para su implantación en los Centros Poblados que tienen un tamaño de población por encima del umbral determinado.

\subsection{5 Índices ponderados de centralidad}

El índice de centralidad permite determinar el grado de centra- lidad (jerarquía) de los Centros Poblados partiendo de la consideración del número y grado de especialización de sus funciones (Del Canto Fresno, 1993, 217). Este índice mide la complejidad en términos no sólo del número de funciones en un centro, sino también de su frecuencia de ocurrencia (Rondinelli, 1988, 173). De acuerdo con estos planteamientos, mientras mayor sea el índice, tanto mayor será su complejidad funcional $y$, por tanto, mayor su jerarquía en el municipio.

Cuadro 11

Clasificación de los índices de centralidad

\begin{tabular}{|l|c|}
\hline CENTROS POBLADOS & $\begin{array}{c}\text { ÍNDICES DE CENTRALIDAD } \\
\text { JERARQUIZADOS }\end{array}$ \\
\hline REMOLINO ORTEGUAZA & 282,3 \\
\hline EL PARÁ & 201,6 \\
\hline NORCASIA & 168,3 \\
\hline SAN GUILLERMO & 168,2 \\
\hline SANTANA LAS HERMOSAS & 157,2 \\
\hline PUERTO ARANGO & 148,8 \\
\hline LA PRIMAVERA & 151,0 \\
\hline LA ESPERANZA & 137,1 \\
\hline CAPITOLIO & 117,7 \\
\hline SAN ANTONIO DE ATENAS & 98,2 \\
\hline MARACAIBO & 73,8 \\
\hline VILLA HERMOSA & 63,8 \\
\hline NUEVA JERUSALÉN & 53,8 \\
\hline SEBASTOPOL & 51,0 \\
\hline AVENIDA EL CARAÑO & 39,7 \\
\hline BAJO SAN GIL & 30,8 \\
\hline VENECIA & 28,8 \\
\hline VILLARAZ & 17,7 \\
\hline FUA & \\
\hline
\end{tabular}

Fuente: Esta investigación.

74 Hugo Hernando Rincón López 
Los centros poblados rurales del municipio de Florencia se clasifican teniendo en cuenta el índice de

Niveles

PRIMER NIVEL:

SEGUNDO NIVEL:

TERCER NIVEL:

\section{Grupos}

$195-283$

$107-194$

$17-106$ centralidad e importancia de las funciones (ver cuadros 10 y 11 , de la siguiente manera:

Agrupando los Centros Poblados por niveles, la clasificación por índice de centralidad queda, así:

\section{Cuadro 12}

Niveles de clasificación por índices de centralidad de los centros poblados

\begin{tabular}{|l|l|c|}
\hline \multicolumn{1}{|c|}{$\begin{array}{c}\text { NIVELES } \\
\text { JERÁRQUICOS }\end{array}$} & \multicolumn{1}{c|}{ CENTROS POBLADOS } & PONDERACIÓN \\
\hline PRIMER NIVEL & Remolino Orteguaza, El Pará & 3 \\
\hline SEGUNDONIVEL & $\begin{array}{l}\text { Norcasia, San Guillermo, Santana, } \\
\text { Las Hermosas, Puerto Arango, } \\
\text { La Primavera, La Esperanza, Capitolio }\end{array}$ & 2 \\
\hline TERCERNIVEL & $\begin{array}{l}\text { San Antonio de Atenas, Maracaibo, } \\
\text { Villa Hermosa Nueva Jerusalén, } \\
\text { Sebastopol, Avenida El Caraño, } \\
\text { Bajo San Gil, Venecia, Villaraz }\end{array}$ & 1 \\
\hline
\end{tabular}

Fuente: Esta investigación.

Remolino Orteguaza y El Pará son los dos asentamientos con mayor centralidad del municipio, es decir, presentan una mayor especialización de sus funciones.

\subsection{Categorización funcional de los Centros Poblados}

\subsubsection{Jerarquía funcional}

La jerarquía funcional ${ }^{11}$ de los centros poblados del municipio de Florencia

11 Grado de desarrollo de un centro poblado en cuanto a su población, número de funciones que ofrece y centralidad en el sistema de asentamientos rurales. 
Cuadro 13

Ponderación de las variables para la jerarquización de los centros poblados

\begin{tabular}{|c|c|c|c|c|}
\hline \multirow[b]{2}{*}{ CDENTROS POBLADOS } & \multicolumn{3}{|c|}{ PONDERACIÓN } & \multirow[b]{2}{*}{$\begin{array}{c}\text { TOTAL } \\
\text { PONDERACIÓN }^{12}\end{array}$} \\
\hline & TAMAÑO & FUNCIONES & CENTRALIDAD & \\
\hline CAPITOLIO & 1 & 1 & 2 & 02 \\
\hline VENECIA & 1 & 1 & 1 & 01 \\
\hline PUERTO ARANGO & 2 & 2 & 2 & 08 \\
\hline REMOLINO ORTEGUAZA & 1 & 3 & 3 & 09 \\
\hline SAN GUILLERMO & 1 & 3 & 2 & 06 \\
\hline SEBASTOPOL & 2 & 1 & 1 & 02 \\
\hline NUEVA JERUSALÉN & 3 & 1 & 1 & 03 \\
\hline AVENIDA EL CARAÑO & 2 & 1 & 1 & 02 \\
\hline LA PRIMAVERA & 2 & 1 & 2 & 04 \\
\hline VILLARAZ & 1 & 1 & 1 & 01 \\
\hline MARACAIBO & 1 & 2 & 1 & 02 \\
\hline NORCASIA & 3 & 3 & 2 & 18 \\
\hline EL PARÁ & 3 & 3 & 3 & 27 \\
\hline VILLA HERMOSA & 1 & 2 & 1 & 02 \\
\hline BAJO SAN GIL & 1 & 1 & 1 & 01 \\
\hline SAN ANTONIO DE ATENAS & 2 & 2 & 1 & 04 \\
\hline SANTANA LAS HERMOSAS & 2 & 3 & 2 & 12 \\
\hline LA ESPERANZA & 2 & 2 & 2 & 08 \\
\hline
\end{tabular}

Fuente: Esta investigación.

se determina teniendo en cuenta la ponderación de las siguientes variables: tamaño poblacional, número de funciones y centralidad de cada asentamiento.

Partiendo de los valores ponderados de cada una de las variables (tamaño, funciones y centralidad) se organizan tres grupos los cuales tienen la siguiente amplitud del intervalo:

Grupo 3: el resultado de las tres variables con valores de 1. Es decir, 1 Grupo 2: el resultado de las tres variables con valores de 2. Es decir, 8 Grupo 1: el resultado de las tres variables con valores de 3. Es decir, 27

\footnotetext{
$\overline{12}$ Para obtener la ponderación total las tres variables se consideran independientes, por tanto se multiplican entre si.
}

76 Hugo Hernando Rincón López 
De esta manera se organizan las siguientes y niveles y grupos y frecuencias de los centros poblados en cada grupo:

$\begin{array}{lcc}\text { NivelesGrupo } & \text { Frecuencias } & \\ \text { PRIMER NIVEL: } & 09-27 & 04 \\ \text { SEGUNDO NIVEL: } & 02-08 & 11 \\ \text { TERCER NIVEL: } & 01 & 03\end{array}$

Agrupando los Centros Poblados por niveles de acuerdo a los puntos ponderados, se obtiene la siguiente jerarquía funcional para los centros poblados del municipio de Florencia:

\section{Cuadro 14}

Jerarquía funcional de los centros poblados del municipio de Florencia

\begin{tabular}{|c|l|l|}
\hline \multicolumn{1}{|c|}{ NIVELES } & JERARQUÍA FUNCIONAL & \multicolumn{1}{c|}{ CENTROS POBLADOS } \\
\hline PRIMER NIVEL & CENTRO RURAL PRINCIPAL & $\begin{array}{l}\text { El Pará, Norcasia, Santana Las } \\
\text { Hermosas, Remolino Orteguaza }\end{array}$ \\
\hline SEGUNDO NIVEL & CENTRO RURAL SECUNDARIO & $\begin{array}{l}\text { Puerto Arango, La Esperanza, } \\
\text { San Guillermo, La Primavera, } \\
\text { San Antonio de Atenas, Nueva } \\
\text { Jerusalén, Maracaibo, } \\
\text { Capitolio, Sebastopol, Avenida } \\
\text { El Caraño, Villa Hermosa }\end{array}$ \\
\hline TERCER NIVEL & CENTRO RURAL BÁSICO & Venecia, Villaraz, Bajo San Gil \\
\hline
\end{tabular}

Fuente: Esta investigación.

\subsubsection{Caracterización de la jerarquía funcional de los centros poblados}

Se han determinado tres categorías de centros poblados que conforman el sistema de asentamientos rurales del municipio: Centro Rural Principal, Centro Rural Secundario, Centro Rural Básico.
1.2.2.1 Centros rurales principales: son los centros poblados más importantes del municipio que concentran un mayor número de habitantes, ofrecen servicios diversos, con un pequeño nivel de especialidad de funciones. En ellos se desarrollan actividades de intercambio comercial entre compradores y productores agrícolas. Tres centros son cabecera de Corregimiento y por tanto, 
cumplen funciones de Policía (Norcasia, Santana Las Hermosas y Remolino Orteguaza) y en otros casos, son puntas de expansión de la frontera agropecuaria (El Pará, Norcasia y Remolino Orteguaza).

1 3.2.2 Centros rurales secundarios: centros poblados dotados de algunos servicios que ofrecen a su población residente en el caserío y a la rural de su entorno inmediato. Algunos son puntas de colonización agropecuaria (San Guillermo, La Esperanza, Villa Hermosa); otros atienden a una población cautiva por razones de religión (Nueva Jerusalén) o son sitios de paso por la carretera Florencia-Neiva (La Primavera y Avenida El Caraño); otros cumplen funciones de consolidación de la colonización (Maracaibo y Santa Las Hermosas); algunos son centros de enlace con otros municipios (Puerto Arango) o turísticos (San Antonio de Atenas), ambos sobre el río Orteguaza; otros de estos asentamientos son antiguos emplazamientos en áreas periféricas a equipamientos del municipio (Capitolio, al lado del aeropuerto; Sebastopol, al lado de los talleres del antiguo Distrito de Obras Públicas por la antigua vía a Neiva).

1.3.2.3 Centros rurales básicos: son centros poblados conformados por un pequeño caserío que alberga servicios mínimos, desempeñando un rol de animación e intercambios con la comunidad rural de su entorno más inmediato. Villaraz es un asentamientos reciente fundado por desplazados en las proximidades de Florencia y aprovechando la dinámica de la construcción de la nueva carretera Florencia-Suaza; Venecia, es un antiguo puerto fluvial sobre el río Orteguaza y Bajo San Gil es un asentamientos que nació de la dinámica económica (cultivo de plátano) y punta de la vía carreteable hacia el sector cordillerano en la parte occidental del municipio.

\subsection{Vínculos e interacciones espa- ciales en el municipio de florencia}

La ciudad de Florencia y el sistema de centros poblados rurales conforman una red compleja de interacciones sociales, económicas, físicas, administrativas y ambientales en el territorio municipal. Estos procesos de interacción están conformados por los vínculos ${ }^{13}$ establecidos por todos los elementos del sistema (la capital municipal y los centros poblados). Cada centro poblado mantiene ciertas relaciones con su área de influencia, la cual se deriva de los nexos funcionales (interrelaciones) que se producen entre los diversos asentamientos y su territorio.

Los centros poblados por pequeños que sean y aislados que estén no

\footnotetext{
13 Corresponde a las relaciones de los habitantes con su medio, con su municipio y/o con otros a través de nexos físicos, económicos, ambientales, sociales, administrativos, etc. (IGAC, 2000, 43).
}

78 Hugo Hernando Rincón López 
pueden subsistir por sí solos, dependen de su entorno territorial para el abastecimiento de recursos básicos (alimentos, agua, madera, materias primas, etc.). Así mismo, los centros ofrecen bienes y servicios (sociales, administrativos, comerciales, equipamientos, infraes-tructura, etc.), estableciéndose una interacción permanente entre ciudad -centro poblado- entorno territorial (campo) para poder subsistir. Estos procesos de interacción permiten que la gente que vive en las áreas rurales (población dispersa) tenga acceso a los servicios, equipamientos, infraestructura y actividades sociales y económicas, las cuales se concentran en los centros poblados y en la ciudad.

\subsubsection{El papel de los vínculos en el desarrollo municipal}

El desarrollo municipal se produce a través del crecimiento y la diversifi-cación de los asentamientos humanos y de la creación de nuevos y más fuertes vínculos entre ellos. En muchas ocasiones la generación de vínculos físicos (carreteras por ejemplo) promueve el despegue y desarrollo de asentamientos deprimidos, en otras, estimula el fortalecimiento de nuevos lugares centrales, y puede, en ciertas ocasiones, generar el decaimiento o la desaparición de algunos centros, por promover el desarrollo de otros. La creación de nuevos vínculos, también, promueve una mayor interacción entre los asentamientos y sus áreas rurales de influencia, lo que puede generar un "efecto de cascada" haciendo posibles otros vínculos que refuercen las interacciones, impulsando una serie de cambios que promueven el desarrollo municipal y regional (por ejemplo vínculos económicos).

El desarrollo municipal, debe buscar un desarrollo endógeno o integrado, que permita equilibrar socioeconómicamente su territorio, contando con la participación activa de las comunidades, incluyendo las más dispersas espacialmente. Así, los propios habitantes contribuirán a potenciar una serie de recursos, fuerzas y capacidades orientados a mejorar su calidad de vida.

\subsubsection{Análisis del sistema vial y de transporte}

El sistema vial y de transporte del municipio está constituido por las vías de comunicación (vías terrestres y fluviales) y por los medios de transporte, y sirve para conectar los asentamientos humanos y proporcionar el acceso de la población rural a los servicios y equipamientos ubicados en los dieciocho centros poblados y en la ciudad de Florencia. El análisis de las características de este sistema permite comprender mejor los vínculos e interacciones establecidos por el movimiento de pasajeros y carga y para determinar el índice de accesibilidad a los diferentes centros poblados del municipio y entre éstos y la capital. 
1.4.2.1 Red vial y medios de transporte terrestre. El análisis de la red vial es de fundamental importancia en la comprensión de los vínculos entre las áreas rurales, los centros poblados y la ciudad de Florencia. El nivel de integración y por tanto, de cohesión y organización del territorio municipal depende en gran medida, del grado de desarrollo de su red de carreteras y caminos.

El municipio de Florencia cuenta con 539 kilómetros de longitud de la red de carreteras (ver Cuadro 15 y mapa 2). Esta red está conformada por tres ejes viales de carácter nacional correspon-diéndole al municipio 97 $\mathrm{km}$, distribuidos así: un tramo de 40 $\mathrm{km}$ perteneciente a la carretera Marginal de la Selva, que atraviesa el territorio municipal de oeste a este, se encuentra en regular estado; un tramo de $36 \mathrm{~km}$ de la vía Florencia-
Guadalupe (antigua vía todavía en funcionamiento), en mal estado y un tramo en servicio de $21 \mathrm{~km}$ de la vía nueva Florencia-Suaza (el resto de esta vía de $22,414 \mathrm{~km}$ entra en funcionamiento en el 2002), está en buen estado; y trece carreteables a nivel municipal con una longitud de $442 \mathrm{~km}$, la mayoría en regular estado (ver cuadro 24).

La densidad vial es de 0.23 kilómetros de carreteras $\left(230 \mathrm{~m} /\right.$ kilómetro $^{2}$ de territorio ${ }^{14}$ ) y teniendo en cuenta la población, la densidad vial es de $0,0034 \mathrm{~km}\left(3,4 \mathrm{~m} /\right.$ habitante $\left.^{15}\right)$. En ambos casos la vialidad es muy baja.

Existe también una red muy densa de caminos que intercomunican las diferentes veredas entre si y con los centros poblados, sobresaliendo el camino que conduce de La Esperanza a San Guillermo dividido en el

\section{Cuadro 16 \\ Infraestructura vial municipal}

\begin{tabular}{|l|c|c|c|}
\hline \multirow{2}{*}{ TIPO DE VÍA } & \multicolumn{2}{|c|}{ TIPO DE MATERIAL Y LONGITUD EN KMS. } & \begin{tabular}{c} 
TOTAL \\
\cline { 2 - 4 }$(\mathbf{k m s})$
\end{tabular} \\
\cline { 2 - 4 } NACIONAL & PAVIMENTO & SIN PAVIMENTO & 97 \\
MUNICIPAL & 61 & 36 & 442 \\
\hline TOTAL & 26 & 416 & $\mathbf{5 3 9}$ \\
\hline
\end{tabular}

Fuente: Instituto Nacional de Vías y Secretaría de Planeación Municipal.

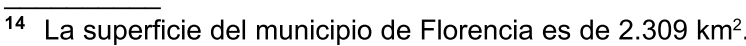

15 La población del municipio para el año 2000 era de 130.500 habitantes (según proyecciones del DANE).

80 Hugo Hernando Rincón López 
tramo La Esperanza-RemolinoOrteguaza $(27 \mathrm{~km})$ y Remolino Orteguaza-San Guillermo $(12,5 \mathrm{~km})$, para una longitud total de $39,5 \mathrm{~km}$.
La red vial constituye el sistema de movilización más importante del municipio y único medio de articulación de los dieciocho centros

\section{Cuadro 17}

Tipo de material y estado de la red vial de centros poblados

\begin{tabular}{|c|c|c|c|c|c|c|c|}
\hline \multirow[b]{2}{*}{ CENTRO POBLADO } & \multicolumn{6}{|c|}{ TIPO DE MATERIAL (Km) Y ESTADO } & \multirow[b]{2}{*}{ 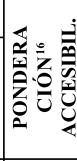 } \\
\hline & $\sum_{i}^{i}$ & ESTADO & $\begin{array}{c}\text { SIN } \\
\text { PAVIM. }\end{array}$ & ESTADO & TOTAL & $\begin{array}{c}\% \\
\text { PAVIM. } \\
\text { SIN }\end{array}$ & \\
\hline EL PARÁ & 21,100 & REGULAR & 38,380 & MALO & 59,480 & 35,5 & 1 \\
\hline REMOLINO ORTEGUAZA ${ }^{17}$ & 4,700 & BUENO & 47,470 & MALO & 52,170 & 9,0 & 1 \\
\hline NORCASIA & 21,100 & REGULAR & 27,880 & MALO & 48,980 & 43,1 & 2 \\
\hline SAN GUILLERMO & 49,000 & BUENO & 93,3 & MALO & 142,300 & 34,4 & 1 \\
\hline SAN ANTONIO DE ATENAS & 4,700 & BUENO & 9,200 & REGULAR & 13,900 & 33,8 & 1 \\
\hline PUERTO ARANGO & 15,700 & BUENO & 0,000 & - & 15,700 & 100,0 & 3 \\
\hline SANTANA LAS HERMOSAS & 4,700 & BUENO & 18,470 & REGULAR & 23,170 & 20,3 & 1 \\
\hline MARACAIBO & 21,100 & REGULAR & 10,550 & MALO & 31,650 & 66,7 & 2 \\
\hline LA ESPERANZA & 4,700 & BUENO & 33,970 & MALO & 38,670 & 12,2 & 1 \\
\hline VILLA HERMOSA & 5,000 & BUENO & 15,100 & MALO & 20,100 & 24,9 & 1 \\
\hline NUEVA JERUSALÉN & 7,000 & REGULAR & 0,000 & - & 7,000 & 100,0 & 3 \\
\hline LA PRIMAVERA & 6,500 & BUENO & 0,000 & - & 6,500 & 100,0 & 3 \\
\hline VENECIA & 11,300 & BUENO & 0,000 & - & 11,300 & 100,0 & 3 \\
\hline SEBASTOPOL & 6,000 & REGULAR & 0,000 & - & 6,000 & 100,0 & 3 \\
\hline BAJO SAN GIL & 13,000 & BUENO & 11,800 & & 24,800 & 52,4 & 2 \\
\hline VILLARAZ & 21,000 & BUENO & 0,000 & - & 21,000 & 100,0 & 3 \\
\hline CAPITOLIO & 7,000 & BUENO & 0,000 & - & 7,000 & 100,0 & 3 \\
\hline AVENIDA EL CARAÑO & 15,000 & BUENO & 0,000 & - & 15,000 & 100,0 & 3 \\
\hline
\end{tabular}

Fuente: Instituto Municipal de Obras Civiles - IMOC y esta investigación.

16 Para la ponderación del porcentaje de las vías pavimentadas se utilizó el siguiente criterio: $71-100 \%$ $=3 ; 41-70 \%=2 ; 9-40 \%=1$.

17 El tramo de $52,170 \mathrm{~km}$ es hasta el sitio Año Nuevo, de ahí hasta Remolino Orteguaza se transita por un camino de $27 \mathrm{~km}$ aproximadamente, para una distancia total de Florencia-Remolino Orteguaza de $79,179 \mathrm{~km}$. 
Cuadro 18. Distancias intramunicipales por carreteras (kms)

\begin{tabular}{|c|c|c|c|c|c|c|c|c|c|c|c|c|c|c|c|c|c|c|c|}
\hline & 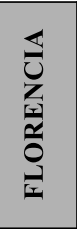 & 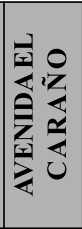 & 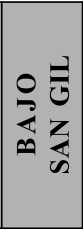 & $\begin{array}{l}\frac{0}{3} \\
0 \\
0 \\
0 \\
0 \\
0\end{array}$ & 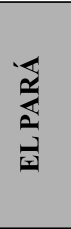 & 这 & 㐫 & 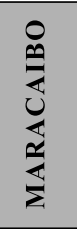 & 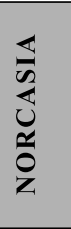 & 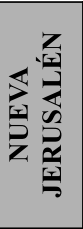 & 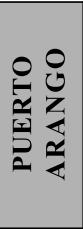 & 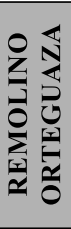 & 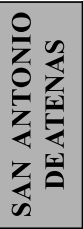 & 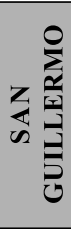 & 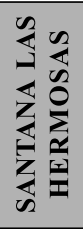 & 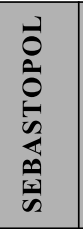 & 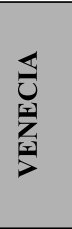 & 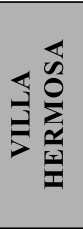 & 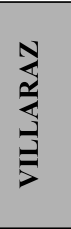 \\
\hline FLORENCIA & 0 & 15,000 & 24,800 & 7,000 & 59,480 & 38,670 & 6,500 & 31,650 & 48,980 & 7,000 & 15,700 & - & 13,900 & & 38,670 & 6,000 & 11,300 & 20,100 & 21,000 \\
\hline AVENIDAEL CARAÑO & 15,000 & 0 & 39,800 & 22,000 & 74,480 & 53,670 & 21,500 & 46,650 & 63,980 & 22,000 & 30,700 & - & 28,900 & - & 53,670 & 21,000 & 26,300 & 35,100 & 36,000 \\
\hline BAJO SANGIL & 24,800 & 39,800 & 0 & 31,800 & 84,280 & 63,470 & 31,300 & 56,450 & 73,780 & 31,800 & 40,500 & - & 38,700 & & 63,470 & 30,800 & 36,100 & 44,900 & 41,800 \\
\hline CAPITOLIO & 7,000 & 22,000 & 31,800 & 0 & 52,480 & 36,270 & 13,500 & 24,650 & 41,980 & 14,000 & 8,700 & - & 11,500 & & 36,270 & 13,000 & 4,300 & 27,100 & 28,000 \\
\hline ELPARÁ & 59,480 & 74,480 & 84,280 & 52,480 & 0 & 93,450 & 65,980 & 27,830 & 10,500 & 66,480 & 43,780 & - & 63,980 & - & 98,750 & 65,480 & 48,180 & 79,580 & 80,480 \\
\hline LAESPERANZA & 38,670 & 53,670 & 63,470 & 36,270 & 93,450 & 0 & 45,170 & 60,920 & 82,950 & 45,670 & 49,67 & - & 24,770 & - & 15,500 & 44,670 & 40,570 & 58,770 & 59,670 \\
\hline LAPRIMAVERA & 6,500 & 21,500 & 31,300 & 13,500 & 65,980 & 45,170 & 0 & 38,150 & 55,480 & 13,500 & 22,200 & - & 20,400 & & 43,170 & 12,500 & 17,800 & 26,600 & 14,500 \\
\hline MARACAIBO & 31,650 & 46,650 & 56,450 & 24,650 & 27,830 & 60,920 & 38,150 & 0 & 17,330 & 38,650 & 15,950 & - & 36,220 & - & 60,920 & 37,650 & 20,350 & 51,750 & 52,650 \\
\hline NORCASIA & 48,980 & 63,980 & 73,780 & 41,980 & 10,500 & 82,950 & 55,480 & 17,330 & 0 & 55,980 & 33,280 & - & 53,450 & - & 78,250 & 54,980 & 38,680 & 60,280 & 69,980 \\
\hline NUEVAJERUSALÉN & 7,000 & 22,000 & 31,800 & 14,000 & 66,480 & 45,670 & 13.500 & 38,650 & 55,980 & 0 & 22,700 & - & 20,900 & & 45,670 & 1,000 & 18,300 & 27,100 & 28,000 \\
\hline PUERTO ARANGO & 15.700 & 30,700 & 40,500 & 8,700 & 43,780 & 49,670 & 22,200 & 15,950 & 33,280 & 22,700 & 0 & 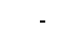 & 20,200 & . & 44,970 & 21,700 & 4,400 & 35,800 & 36,700 \\
\hline REMOLINO ORTEGUAZA & - & - & - & - & - & - & - & - & - & & & 0 & - & - & - & & & 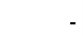 & \\
\hline SANANTONIO DEATENAS & 13,900 & 28,900 & 38,700 & 11,500 & 63,980 & 24,770 & 20,400 & 36,220 & 53,450 & 20,900 & 20,200 & - & 0 & & 9,270 & 19,900 & 15,800 & 34,000 & 34,900 \\
\hline SAN GUILLERMO & & & & & & - & & & & & & - & & 0 & - & & & & \\
\hline SANTANALAS HERMOSAS & 38,670 & 53,670 & 63,470 & 36,270 & 88,750 & 15,500 & 43,170 & 60,920 & 78,950 & 45,670 & 44,970 & - & 9,270 & - & 0 & 44,670 & 44,800 & 58,770 & 59,670 \\
\hline SEBASTOPOL & 6,000 & 21,000 & 30,800 & 13,000 & 65.480 & 44,670 & 12,500 & 37,650 & 54,980 & 1,000 & 21,700 & - & 19,900 & & 44,670 & 0 & 17,300 & 26,100 & 27,000 \\
\hline VENECIA & 11.300 & 26,300 & 36,100 & 4,300 & 48,180 & 40,570 & 17,800 & 20,350 & 38,680 & 18,300 & 4,400 & - & 15,800 & & 44,800 & 17,300 & 0 & 31,400 & 32,300 \\
\hline VILLA HERMOSA & 20,100 & 35,100 & 44,900 & 25,100 & 79,580 & 58,770 & 26,600 & 51,750 & 60,280 & 27,100 & 35,800 & - & 34,000 & - & 58,770 & 26,100 & 31,400 & 0 & 41,100 \\
\hline VILLARAZ & 21,000 & 36,000 & 41,100 & 28,000 & 80,480 & 59,670 & 14,500 & 52,650 & 69,980 & 28,000 & 36,700 & - & 34,900 & & 59,670 & 27,000 & 32,300 & 41,100 & 0 \\
\hline
\end{tabular}

Fuente: Secretaría de Planeación Municipal y esta investigación. 
poblados con la capital (ver cuadro 18), ya que por vía fluvial sólo existe comunicación con el sur del municipio a través del río Orteguaza y en este sector no existen centros poblados.

Los centros poblados de Remolino Orteguaza y San Guillermo, por estar localizados en la parte más septentrional del municipio en área de Reserva Forestal de la Amazonia, carecen de vías carreteables que los comunique directamente con Florencia, su acceso se realiza a través de un camino hasta La Esperanza, el cual se encuentra en mal estado empeorando en épocas de lluvias. San Guillermo tiene una vía carreteable de acceso por el departamento del Huila, que lo interconecta con el centro urbano del municipio de Garzón y de éste con Florencia.

El transporte de pasajeros por vía terrestre está organizado por la Sociedad Terminal de Transportes de Florencia S.A., que afilia empresas y adjudica rutas en todo el territorio municipal. Las empresas que prestan servicios a los centros poblados son: Coomotor Florencia y Cootranscaquetá, con servicio de buses y mixtos, y Transyarí y Cootransflorencia, con servicio de taxis.

El transporte de carga no está organizado como el de pasajeros a excepción del transporte de ganado que lo centraliza y controla la empresa Central de Ferias y Mataderos COFEMA.
Existen otros medios de transporte alternativo como son los vehículos particulares y las motocicletas que poseen algunos pobladores asentados a largo de las carreteras, pero debido su mínima cantidad y carácter privado no tiene gran significancia en la movilidad de personas y cargas; al contrario del transporte caballar y mular que tiene una alta importancia en la movilización Inter-veredal y entre éstas y los centros poblados. Es decir, este medio de locomoción constituye un sistema de alimentación de cargas y pasajeros de los vehículos automotores que se desplazan entre centros poblados y los comunican con la capital.

\subsubsection{Sistema fluvial $y$ medios de} transporte acuático. El río Orteguaza, afluente principal del río Caquetá constituye el único eje fluvial del municipio. Por esta vía acuática se movilizan personas y cargas hacia el sureste del municipio, teniendo a Puerto Arango como el punto de enlace con Florencia. A nivel municipal el movimiento de pasajeros y carga son muy escasos debido a la baja densidad de población de este sector; pero a nivel Inter-municipal, por el río se moviliza un importante tráfico hacia las cabeceras municipales de Milán y Solano y otros centros poblados importantes del Caquetá y Putumayo, tales como San Antonio de Getuchá, Granario, Remolino Orteguaza, la base militar de Tres Esquinas, Monunguete y La Maná en el Caquetá y La Tagua, Mandur, Mayoyoque y Santa Rosa en el Putumayo. 
El transporte de pasajeros se realiza en botes (deslizadores) y canoas con motor fuera de borda y el de carga en lanchas y lanchones de mayor capacidad. Las empresas fluviales que prestan estos servicios son: Expreso Challenger, Transfluvial del Sur y Transporte Fluvial Solano.

1.4.2.3 Análisis de accesibilidad: este análisis permite conocer la eficiencia del sistema de transportes en el municipio para poder determinar el grado de accesibilidad de cada centro poblado respecto a la capital
(Florencia), teniendo en cuenta las variables tiempo y distancia, las cuales llevan implícitas las condiciones físicogeográficas, los medios de transporte y el estado de las vías.

Para el cálculo de las distancias y tiempos de los centros poblados de Remolino Orteguaza y San Guillermo que no están conectados por vía terrestre a Florencia, se hizo lo siguiente: para Remolino Orteguaza se calculó la distancia por camino (27 $\mathrm{km})$ y el tiempo invertido a pie hasta el caserío Año Nuevo (punta de la

\section{Cuadro 19}

Distancias y tiempos de los centros Poblados con respecto a Florencia

\begin{tabular}{|l|c|c|c|}
\hline \multicolumn{1}{|c|}{ CENTRO POBLADO } & $\begin{array}{c}\text { DISTANCIA A } \\
\text { FLORENCIA } \\
\text { (kms de vía) }\end{array}$ & $\begin{array}{c}\text { TIEMPO } \\
\text { PROMEDIO }\end{array}$ & $\begin{array}{c}\text { PONDERACIÓN } \\
\text { EN FUNCIÓN } \\
\text { DEL TIEMPO }\end{array}$ \\
\hline EL PARÁ & 59,480 & $3: 50$ & 2 \\
\hline REMOLINO ORTEGUAZA & 79,170 & 11,45 & 1 \\
\hline NORCASIA & 48,980 & $3: 20$ & 2 \\
\hline SAN GUILLERMO & 142,300 & $6: 40$ & 1 \\
\hline SAN ANTONIO DE ATENAS & 13,900 & $0: 50$ & 3 \\
\hline PUERTO ARANGO & 15,700 & $0: 25$ & 3 \\
\hline SANTANA LAS HERMOSAS & 23,170 & $1: 45$ & 3 \\
\hline MARACAIBO & 31,650 & $1: 50$ & 3 \\
\hline LA ESPERANZA & 38,670 & $2: 45$ & 3 \\
\hline VILLA HERMOSA & 20,100 & $1: 30$ & 3 \\
\hline NUEVA JERUSALÉN & 7,000 & $0: 12$ & 3 \\
\hline LA PRIMAVERA & 6,500 & $0: 8$ & 3 \\
\hline VENECIA & 11,300 & $0: 18$ & 3 \\
\hline SEBASTOPOL & 6,000 & $0: 10$ & 3 \\
\hline BAJO SAN GIL & 24,800 & $2: 15$ & 3 \\
\hline VILLARAZ & 21,000 & $0: 35$ & 3 \\
\hline CAPITOLIO & 7,000 & $0: 5$ & 3 \\
\hline AVENIDA EL CARAÑ & 15,000 & $0: 25$ & \\
\hline
\end{tabular}

Fuente: Instituto Municipal de Obras Civiles - IMOC y esta investigación.

84 Hugo Hernando Rincón López 
carretera) y de este sitio hasta el centro poblado La Esperanza, en un tramo de $13,5 \mathrm{~km}$ y se le agregó luego, la distancia y tiempo calculados entre Florencia y La Esperanza. Para San Guillermo se utilizó la ruta San Guillermo-Garzón $(17,3 \mathrm{~km}$ de vía municipal en mal estado) y GarzónFlorencia $(125 \mathrm{~km}$ de vía nacional en regular estado), para un total de 142.3 km (ver cuadro 17).

Los centros poblados con mayor nivel de accesibilidad a la ciudad de Florencia, según la distancia y el tiempo corresponden a aquellos que se encuentran a menos de treinta minutos, estos son: Capitolio, La Primavera, Sebastopol, Nueva Jerusalén, Venecia, Avenida El Caraño, y Puerto Arango; mientras que los que presentan menor accesibilidad son: Remolino Orteguaza, San Guillermo, El Pará y Norcasia (ver cuadro 19 y mapa 3). En este caso, el nivel de accesibilidad se determina en función de la distancia y en el tiempo invertido, sin embargo, la condición "estado de las vías" (ver cuadro 18), influye mucho en la velocidad de desplazamiento, hecho que se refleja en el tiempo invertido. Nótese por ejemplo, que Puerto Arango con una distancia de $15,7 \mathrm{~km}$ está a 25 minutos de Florencia mientras que de San Antonio de Atenas con 13,9 km, se invierten 50 minutos a Florencia, es decir, que con apenas $1,8 \mathrm{~km}$ de diferencia, se invierte el doble de tiempo a San Antonio de
Atenas en relación de Puerto Arango, y Villaraz $(21 \mathrm{~km})$ frente a Bajo San Gil $(24,8 \mathrm{~km})$ con una diferencia de $3,8 \mathrm{~km}$, a Bajo San Gil se invierte 1:40 minutos más que a Villaraz.

Aunque la variable espacial "distancia ${ }^{18}$ entre dos lugares" viene perdiendo significación en las áreas más desarrolladas por el mejoramiento de las vías, el "efecto túnel", etc., en el sector rural del municipio de Florencia sigue teniendo un peso importante a la hora de determinar el tiempo invertido entre los centros poblados y la capital, fundamentalmente por el estado de las vías que no permiten desarrollar altas velocidades.

1.4.2.4 Análisis de movilidad. Se entiende por movilidad, la magnitud de desplazamientos de personas, bienes $\mathrm{y}$ servicios a través del territorio municipal utilizando el sistema de transportes existente (red vial y fluvial y los medios de transporte), la cual está en relación directa con el nivel de accesibilidad de los centros poblados.

Generalmente la población se moviliza para satisfacer sus necesidades, las cuales están en función de la oferta y demanda de bienes y servicios ofrecidos bien sea por el centro poblado más próximo o por el lugar que ofrezca mejores y mayores posibilidades de satisfacer esas necesidades; como también existen movimientos

18 Importancia de la distancia como principio de la dimensión espacial. 
Cuadro 20. Movimiento de pasajeros/promedio semana, 2000

\begin{tabular}{|l|c|c|}
\hline \multicolumn{1}{|c|}{ CENTRO POBLADO } & PASAJEROS/SEMANA & PONDERACIÓN $^{21}$ \\
\hline PUERTO ARANGO & 740 & 2 \\
\hline NORCASIA & 352 & 1 \\
\hline SANTANA LAS HERMOSAS & 250 & 1 \\
\hline LA ESPERANZA & 220 & 1 \\
\hline EL PARÁ & 208 & 1 \\
\hline SEBASTOPOL & 206 & 1 \\
\hline SAN ANTONIO DE ATENAS & 204 & 1 \\
\hline VILLARAZ & 190 & 1 \\
\hline NUEVA JERUSALÉN & 170 & 1 \\
\hline BAJO SAN GIL & 150 & 1 \\
\hline MARACAIBO & 140 & 1 \\
\hline VILLA HERMOSA & 140 & 1 \\
\hline LA PRIMAVERA & 106 & 1 \\
\hline AVENIDA EL CARAÑO & 98 & 0 \\
\hline VENECIA & 94 & 0 \\
\hline CAPITOLIO & 60 & \\
\hline REMOLINO ORTEGUAZA & - & \\
\hline SAN GUILLERMO & - & \\
\hline
\end{tabular}

Fuente: Terminal de Transportes de Florencia S. A.

Cuadro 21. Volúmenes de tránsito municipal/promedio semana, 2000

\begin{tabular}{|l|c|l|c|}
\hline \multicolumn{1}{|c|}{ CENTRO POBLADO } & VEHÍCULOS/SEMANA & TIPO DE VEHÍCULOS & PONDERACIÓN ${ }^{22}$ \\
\hline PUERTO ARANGO & 126 & Taxis & 3 \\
\hline NUEVA JERUSALÉN & 28 & Colectivos & 1 \\
\hline SEBASTOPOL & 28 & Colectivos & 1 \\
\hline EL PARÁ & 14 & Mixtos & 1 \\
\hline NORCASIA & 14 & Mixtos & 1 \\
\hline MARACAIBO & 14 & Mixtos & 1 \\
\hline SAN ANTONIO DE ATENAS & 7 & Mixtos & 1 \\
\hline SANTANA LAS HERMOSAS & 7 & Mixtos & 1 \\
\hline LA ESPERANZA & 7 & Camperos & 1 \\
\hline VILLA HERMOSA & 7 & Mixtos & 1 \\
\hline BAJO SAN GIL & 7 & Camperos & 1 \\
\hline VILLARAZ & 7 & - & 1 \\
\hline REMOLINO ORTEGUAZA & - & - & 0 \\
\hline SAN GUILLERMO & - & Buses, Mixtos, Taxis & \\
\hline LA PRIMAVERA & Sitio de paso & Buses, Mixtos, Taxis & 3 \\
\hline VENECIA & Sitio de paso & Buses, Mixtos, Taxis & 3 \\
\hline CAPITOLIO & Sitio de paso & Buses & 3 \\
\hline AVENIDA EL CARAÑO & Sitio de paso & \\
\hline Fuente: Trin & \\
\hline
\end{tabular}

Fuente: Terminal de Transportes de Florencia S.A.

21 Para la ponderación se definieron 3 grupos de acuerdo con el movimiento de pasajeros/semana 1: 60-287; 2: 288-514 y 3: 515-740.

22 Para la ponderación se definieron 3 grupos: 1: 7-47; 2: 48-87 y 3: 88-126. A los sitios de paso se les asignó el valor de 3 , porque aunque no existen rutas específicas para esos lugares por ellos pasan todos los vehículos que llevan otros destinos dentro y fuera del municipio a los cuales los habitantes pueden acceder.

86 Hugo Hernando Rincón López 
poblacionales por interacción social entre familiares y amigos. Para estos desplazamiento utilizan los medios de transporte disponibles, que a su vez se organizan en relación directa con el volumen de población movilizada, definiendo así, las frecuencias y dirección de los flujos.

Para este caso, la movilidad se analiza por medio de los flujos, frecuencia e intensidad del transporte municipal (movimiento de pasajeros ${ }^{19}$ y volumen de tránsito $\left.{ }^{20}\right)$.

La red vial municipal tiene como eje central la carretera marginal del selva que cruza al municipio de occidente a oriente pasando por Florencia, y de ella se desprenden los ramales que interconectan los centros poblados cordilleranos en el norte del municipio y los que conectan las veredas del sur, hacia la planicie amazónica.

Por esta estructura de la vialidad municipal, todas las relaciones y movimientos entre los centros urbanos y con la capital se dan en el mismo sentido de la red, terminando siempre en ella, evidencián-dose de esta forma la fuerte dependencia y centralidad que ejerce la ciudad de Florencia sobre todo el sistema de asentamientos humanos del municipio.
El movimiento de pasajeros y los volúmenes de tránsito (ver cuadros 20 y 21 y mapas 4 y 5) indican, en cierto grado, la importancia funcional de los centros poblados del municipio. Por ejemplo, Puerto Arango presenta los mayores volúmenes de pasajeros y tránsito de vehículos, situación explicable por el hecho de ser puerto fluvial y nodo de conexión de Florencia con los municipios de Milán y Solano y algunos lugares del departamento de Putumayo, siguiendo la ruta de los ríos Orteguaza-Caquetá.

El Pará y La Esperanza, son centros poblados de mucha actividad por ser asentamientos ubicados en las puntas de las vías y de apoyo a los frentes de colonización en el sector cordillerano. Norcasia y Santana Las Hermosas, a pesar de no estar en las puntas, aglutinan un sector de colonización más antiguo y por tanto, con una población un poco más estable que permiten equipamientos más especializados, como colegios, por ejemplo, que dinamizan la movilidad de la población.

Los centros poblados periféricos a Florencia, tienen transporte público urbano de baja frecuencia, tal es el caso de Sebastopol y Nueva Jerusalén, y los demás centros, como La

19 Para el movimiento de los pasajeros se incluye el promedio de personas que se movilizan semanalmente en los dos sentidos (origen y destino, desde Florencia al centro poblado y viceversa).

20 El volumen de tránsito es un promedio semanal solamente de los vehículos de transporte público que movilizan pasajeros. Es decir, no se tienen en cuenta el transporte de carga ni vehículos de uso personal. 
Primavera, Avenida El Caraño, Capitolio y Venecia no tienen rutas definidas por ser sitios de paso; la movilización de personas y carga la hacen a través del transporte intermunicipal que es permanente e intenso.
1.4.2.5 Síntesis del análisis de los vínculos e interacciones entre la capital y los centros poblados. Para determinar el nivel de los vínculos establecidos por el sistema de asentamientos humanos del municipio se ponderan las variables analizadas: accesibilidad, distancias y tiempos y movilidad (movimiento de pasajeros y volumen de tránsito).

\section{Cuadro 22}

Ponderación de variables para determinar vínculos de los centros poblados

\begin{tabular}{|c|c|c|c|c|c|}
\hline \multirow[b]{2}{*}{ CENTROS POBLADOS } & \multicolumn{4}{|c|}{ PONDERACIÓN } & \multirow{2}{*}{$\begin{array}{c}\text { TOTAL } \\
\text { PONDERACIÓN }\end{array}$} \\
\hline & ACCESIBILID. & TIEMPOS & PASAJEROS & TRÁNSITO & \\
\hline PUERTO ARANGO & 3 & 3 & 3 & 3 & 12 \\
\hline NUEVA JERUSALÉN & 3 & 3 & 1 & 1 & 08 \\
\hline SEBASTOPOL & 3 & 3 & 1 & 1 & 08 \\
\hline EL PARÁ & 1 & 2 & 1 & 1 & 05 \\
\hline NORCASIA & 2 & 2 & 2 & 1 & 07 \\
\hline MARACAIBO & 2 & 3 & 1 & 1 & 06 \\
\hline SAN ANTONIO DE ATENAS & 1 & 3 & 1 & 1 & 06 \\
\hline SANTANA LAS HERMOSAS & 1 & 3 & 1 & 1 & 06 \\
\hline LA ESPERANZA & 1 & 3 & 1 & 1 & 06 \\
\hline VILLA HERMOSA & 1 & 3 & 1 & 1 & 06 \\
\hline BAJO SAN GIL & 2 & 3 & 1 & 1 & 07 \\
\hline VILLARAZ & 3 & 3 & 1 & 1 & 08 \\
\hline REMOLINO ORTEGUAZA & 1 & 1 & 0 & 0 & 02 \\
\hline SAN GUILLERMO & 1 & 1 & 0 & 0 & 02 \\
\hline LA PRIMAVERA & 3 & 3 & 1 & 3 & 10 \\
\hline VENECIA & 3 & 3 & 1 & 3 & 10 \\
\hline CAPITOLIO & 3 & 3 & 1 & 3 & 10 \\
\hline AVENIDA EL CARAÑO & 3 & 3 & 1 & 3 & 10 \\
\hline
\end{tabular}

Fuente: Esta investigación.

Considerando el total de vínculos ponderados, se determinaron cuatro niveles de interacciones en el sistema de asentamientos humanos del municipio de Florencia, considerando los siguientes grupos y frecuencias:

88 Hugo Hernando Rincón López 


$\begin{array}{lcc}\text { Nivel } & \text { Grupo } & \text { Frecuencia } \\ \text { PRIMER NIVEL: } & 10-12 & 5 \\ \text { SEGUNDO NIVEL: } & 07-09 & 5 \\ \text { TERCER NIVEL: } & 05-6 & 6 \\ \text { CUARTO NIVEL: } & 02-4 & 2\end{array}$

Agrupando los centros poblados por niveles de acuerdo a los puntos ponderados, se obtiene los siguientes tipos de interacciones entre los centros poblados y la ciudad de Florencia:

Cuadro 23

Tipos de interacciones de los centros poblados con Florencia

\begin{tabular}{|c|c|l|}
\hline \multicolumn{1}{|c|}{ NIVELES } & TIPOS DE INTERACCIÓN & \multicolumn{1}{c|}{ CENTROS POBLADOS } \\
\hline PRIMER NIVEL & FUERTE & $\begin{array}{l}\text { PUERTO ARANGO, LA PRIMAVERA, } \\
\text { VENECIA, CAPITOLIO Y AVENIDA } \\
\text { EL CARAÑO }\end{array}$ \\
\hline SEGUNDO NIVEL & MODERADA & $\begin{array}{l}\text { NUEVA JERUSALÉN, SEBASTOPOL, } \\
\text { VILLARAZ, NORCASIA Y BAJO SAN GIL }\end{array}$ \\
\hline TERCER NIVEL & DÉBIL & $\begin{array}{l}\text { MARACAIBO, SAN ANTONIO DE } \\
\text { ANTENAS, SANTANA LAS HERMOSAS, } \\
\text { LA ESPERANZA VILLA HERMOSA } \\
\text { Y EL PARÁ }\end{array}$ \\
\hline CUARTO NIVEL & MUY DÉBIL & $\begin{array}{l}\text { REMOLINO ORTEGUAZA Y SAN } \\
\text { GUILLERMO }\end{array}$ \\
\hline
\end{tabular}

Fuente: Esta investigación.

Florencia, capital municipal y departamental, constituye el núcleo urbano articulador del sistema municipal de centros poblados a través de la red de vías terrestres y fluviales (río Orteguaza). En su calidad de Centro Subregional de segundo orden dentro de la organización actual y funcional del espacio colombiano (IGAC, 1998), Florencia cuenta con importantes equipamientos urbanos de servicios especializados, administrativos, económicos, socioculturales y turísticos que la convierten en el principal centro urbano centralizador y dinamizador de las interacciones espaciales intramunicipales, intermunicipales, regionales y nacionales representadas por flujos ${ }^{23}$ de personas, mercancía, información, capital, etc.).

${ }^{23}$ Es una medida de los vínculos, define tipo, magnitud y dirección de los elementos que se movilizan. Se refiere a los movimientos o circulación de bienes y servicios, de capital, de personas, de energía de un espacio a otro en desplazamientos parciales o permanentes (IGAC, 2000, 40). 
A nivel de los vínculos intermunicipales, existe solamente un centro poblado que sirve de enlace con otras cabeceras municipales, generando un tipo de interacción espacial fuerte. Este centro es Puerto Arango, asentamiento de segundo orden de jerarquía funcional del municipio, puerto sobre el río Orteguaza y lugar de enlace entre la ciudad de Florencia y los municipios de Milán y Solano.

Existen igualmente, otros centros poblados con un buen grado de integración a Florencia, especialmente por factores de proximidad, vialidad y fuente de trabajo en la capital, estos son: La Primavera, Venecia, Capitolio y Avenida El Caraño.

En el otro extremo, se ubican los centros poblados con interacciones muy débiles con la capital (áreas mal integradas), caso de San Guillermo y Remolino Orteguaza, los cuales debido a la carencia de infraestructura vial, tienen muy poca participación en el ámbito municipal por lo que aparecen como áreas desintegradas del sistema de asentamientos humanos del municipio. Esta situación requiere que con urgencia la continuación y terminación del tramo La Esperanza San Guillermo, pasando por Remolino
Orteguaza, interconectando al municipio de Florencia con el municipio de Garzón, en el departamento del Huila, y de esta forma articular esta amplia zona a la dinámica socioeconómica del departamento y de país.

En general, las interacciones espaciales del sistema de asentamientos humanos del municipio de Florencia, muestran la existencia de un desequilibrio funcional del territorio municipal. La macrocefalia de Florencia absorbe todas las actividades, pero al mismo tiempo y a pesar de la fuerte centralización no polariza todo su espacio geográfico adecuadamente. Por esta razón, las zonas ubicadas en los extremos norte y sur $^{24}$ del municipio, presentan baja integración espacial.

\section{Organización actual y funcional del municipio de Florencia}

\subsection{Regionalización actual}

En la estructuración socioespacial del municipio, el Estado ha ejercido un papel hegemónico ${ }^{25}$ interviniendo sobre el territorio a través de políticas públicas, que han determinando un

\footnotetext{
24 Zonas marginadas (ver cuadro xx): parte septentrional: San Guillermo y Remolino Orteguaza; parte meridional: no existen centros poblados y hay baja densidad vial.

25 Sin embargo, no se puede desconocer el importante papel desempeñado por la colonización y los ciclos extractivos en la estructuración actual del territorio municipal, toda vez, que diferentes actores y agentes sociales, diferentes al Estado, intervinieron significativamente en él.
}

90 Hugo Hernando Rincón López 
tipo de organización acorde con sus necesidades de control político y administrativo. En desarrollo del proceso de descen-tralización el Estado abrió la posibilidad de que los municipios dividieran su territorio rural en Corregimientos, estable-ciendo un sistema de regionalización para efectos de obtener coherencia y unidad en la toma de las decisiones y en la ejecución de sus acciones políticoadministrativas.

Atendiendo estos criterios de división político-administrativa del territorio y en cumplimiento de la Ley 136 de 1994 (Nuevo Régimen Municipal Colombiano) y con el fin de mejorar la prestación de los servicios y asegurar la participación de la ciudadanía en el manejo de los asuntos públicos de carácter local, el Concejo municipal mediante Acuerdo 020 de junio de 1995, subregionalizó el municipio en siete corregimientos (ver mapa 7), así:

- Corregimiento San Pedro: con Norcasia (centro poblado) como cabecera corregimental e integrado por las siguientes veredas: Maracaibo, La Primavera, La Victoria Baja, La Victoria Alta, El Pielroja, Calamar, Manzanares, Dos Valles, Norcasia, Vista Hermosa, Sinaí, Begonia, El Rosal, San Pablo, Buenos Aires, El Pará, Palmarito, la Florida, San José, Alto San Pedro, San Lorenzo y Tovar Zambrano.

- Corregimiento Orteguaza: con Santana Las Hermosas (centro poblado) como cabecera corregimental e integrado por las siguientes veredas: La Astilla, La Florida, San Cristóbal Bajo, San Cristóbal Alto, El Hoyo, El Roble, La Paila, Alto Reflejo, Reflejo, Irlanda, Agualinda, Santana Las Hermosas, El Diamante, Chontaduro, Sinaí Bajo, El Cedro, La Ilusión, Villanueva, Alto Palmar, Las Torres, La Esperanza, Año Nuevo y Alejandría parte sur.

- Corregimiento El Danubio: con la cabecera corregimental en Remolino Orteguaza (centro poblado) e integrado por las siguientes veredas: Alejandría parte norte, La Estrella, El Ural, Ramos, Los Alpes, Miraflores, Los Alpes, Río Bravo, El Carmen, Turín, Quebradón, San Guillermo y Remolino Orteguaza.

- Corregimiento El Caraño: con la cabecera corregimental en Avenida El caraño (centro poblado) e integrado por las siguientes veredas: El Dedito, Bajo Travesías, Palmichal, San Luis, Tarqui, Agua Negra, El Limón La Primavera, Las Doradas, San Francisco, Alto Paraíso, Paraíso, Nueva Jerusalén, El Caraño, Travesías, Cristalina, La Paz, Santa Elena, Villaraz, Vuelta al Cigarrillo, Agua Bonita, Sucre, Quindío, Santo Ángel, Sebastopol, El Convenio, Alto Brasil, El Horizonte, Los Guayabos, Caldas, Alto Caldas, La Carbona, Nueva Paz, Avenida El Caraño, Bello Horizonte y El Salado. 
- Corregimiento Santo domingo: con la cabecera corregimental en Santo Domingo (vereda) e integrado por las siguientes veredas: Turbay, Las Minas, El Jardín, Villa Hermosa, Damas Abajo, San Isidro, Barcelona, Alto San Gil, Bajo San Gil, Finlandia, La Arenosa, Villa Flores, Argelia, Holanda, Costa Rica, Santander, Damas Arriba, Alto Bonito, Resguardo Honduras, Las Congas, El Terminal y Santo Domingo.

- Corregimiento San Martín: con la cabecera corregimental en Campucana (vereda) e integrado por las siguientes veredas: San Martín, La Miranda, El Venado, Turbia Alta, Turbia Baja, Colombia, San Juan del Barro, Bodoquero, Tominejo, La Victoria, Campucana, La Aurora.

- Corregimiento Venecia: con la cabecera corregimental en Puerto Arango (centro poblado) e integrado por las siguientes veredas: San José de Canelos, Capitolio, Venecia, Alto Venecia, Alto Canelos, Germania, Balcanes, Puerto Arango, La Esperanza, La Paz, La Independencia, La libertad y El Vergel.

Esta división del municipio en corregimientos no obedece a vínculos claramente establecidos que conformen una región funcional en torno a un nodo o polo de atracción, sino a las necesidades de organizar político-administrativamente el territorio, pues según la legislación, los Corregimientos constituyen "circunscrip-ciones electorales" (Colombia. Congreso de la República. Ley 136 de 1994, artículo 121), para elegir sus Juntas Adminis-tradoras Locales.

De hecho, una vez constituidos legalmente los Corregimientos se establecen unos vínculos políticos y administrativos entre las veredas y la cabecera corregimental, reflejados en las relaciones formales y estructurales de gobierno. Vínculos que en algunos casos, tales como el de los Corregimientos de San Martín y Santo Domingo, no desencadenan nuevos vínculos debido a que la sede del corregidor se ubica en un lugar que no ofrece ningún otro tipo de servicios.

La organización territorial debe concebirse dentro del concepto del "desarrollo endógeno o integrado", como concluyen Uphof y Esman (citado por Rondinelli, 1988,200), "la organización para el desarrollo rural debe ser vista como un sistema de instituciones que desempeñan varias funciones". Desde este punto de vista, el Corregimiento debe servir para promover nuevas funciones orientadas a fortalecer un desarrollo rural integrado, alrededor de un asentamiento estratégico que permita el acceso de la población rural a los bienes y servicios de los lugares centrales. Esta organización podría estructurarse a partir de las "Unidades de Funcionamiento Espacial" que muestran cómo se organiza el territorio 
municipal a partir de uno o varios centros poblados, conformando unidades interrelacionadas por diferentes vínculos, permitiendo "orientar la localización de infraestructura vial para articular la prestación de servicios, analizar las deficiencias en cuanto a la articulación con otras zonas y servir como instrumento para mejorar el funcionamiento dentro del municipio". Pero también, señala las áreas que no se encuentran polarizadas al interior del municipio, para poder definir acciones prioritarias para su integración.

\subsection{Unidades de funcionamiento espacial}

Las Unidades de Funcionamiento Espacial, según el IGAC (2000, 42) se definen como "el espacio polarizado por un centro, en el cual se establece una dinámica de interacciones e interrela-ciones de tipo físico (carreteras y medios de comunicación en general), sociales, económicos, movimientos de población, transferencia de tecnología, financieros, de prestación de servicios sociales y de carácter político, administrativo y organizativo, entre el espacio y el centro, que constituyen vínculos". De acuerdo con esta definición, estas unidades se determinan teniendo en cuenta la demanda de bienes y servicios y la movilidad de la población hacia un centro poblado que ofrezca posibilidades de satisfacer algunas demandas de la población, por su proximidad y facilidad de acceso.

Las Unidades de Funcionamiento Espacial del municipio de Florencia, reflejan los vínculos establecidos por el sistema de asentamientos humanos de acuerdo con el nivel de jerarquía funcional de los centros poblados y los vínculos e interacciones con la capital y las áreas rurales circunvecinas, expresados a través de la movilidad poblacional (movimiento de personas y volumen de tránsito) y accesibilidad mediante la red de comunicaciones existente.

De acuerdo con los anteriores criterios, se identificaron y delimitaron las siguientes Unidades de Funcionamiento Espacial (ver mapa 8):

\subsubsection{Unidad Florencia - La Prima- vera - Nueva Jerusalén - Sebastopol - Capitolio}

Esta unidad está localizada alrededor de la ciudad de Florencia cubriendo una extensa zona que se extiende hacia el oriente hasta Capitolio y hacia el norte hasta la vereda El Convenio, Travesías y Los Guayabos donde se encentran varios centros poblados, tales como La Primavera, Capitolio, Nueva Jerusalén y Sebastopol, los dos últimos en vías de conurbación con Florencia. Hacia el occidente se extiende hasta la vereda Alto San Gil y hacia el sur hasta el límite con los municipios de Morelia y Milán. 
En la parte suroccidental de la unidad no hay ningún centro poblado que polarice internamente este sector, la población dispersa acude directamente a Florencia en busca de bienes y servicios utilizando varias vías carreteables que atraviesan esta zona, o directamente por la Marginal de la Selva. Este sector, es netamente ganadero y hace parte del piedemonte y de la planicie amazónica. Hacia el costado más occidental, sobre la quebrada Mochilero (afluente del Bodoquero) se ubica el Centro de Investigaciones de CORPOICA, institución que adelanta estudios sobre sistemas de producción sostenibles en la región, realiza transferencia tecnológica y desarrollo asesoría y capacitación a campesinos del Caquetá.

Prácticamente Florencia proporciona todos los bienes y servicios a la población de esta unidad, no obstante, los centros poblados vinculados suministran servicios básicos para satisfacer necesidades primarias de su población concentrada y dispersa en el área rural que no va más allá del límite veredal.

Dentro de esta área de influencia se encuentran las veredas La Primavera, Nueva Jerusalén, Sebastopol, La Estrella, La Batea, Capitolio, La Batalla, La Florida, El Dedito, La Holanda, San Juan del Barro, Colombia, Damas Abajo, Agua Negra, Brasil, Alto Brasil, Vuelta de Cigarrillo, La Chipa, Campucana,
Villa Flores, Caldas, Caldas Oriental, Alto Caldas y San Luis, El Convenio, Travesías, Los Guayabos, Alto San Gil, Las Congas, Villa del Río, Holanda, la Arenosa, Travesías, Bajo Travesías, Alto Bonito, Agua Bonita, Finlandia, Argelia, La Aurora, San Isidro, Costa Rica, Las Minas, Santander, El Venado, Santo Domingo, La Viciosa, Macagual, La Turbia Arriba, La Turbia Abajo, San Martín, Tominejo, La Miranda, El Bodoquero y La Argentina, La Carbona, El Limón y El Salado.

Existe un alto grado de accesibilidad utilizando las vías nacionales (FlorenciaSuaza, Florencia-Guadalupe y Marginal de la Selva). El mayor movimiento de personas y carga se realiza el domingo para comercializar en la central de abastos de Florencia algunos excedentes de la producción agropecuaria: plátano, yuca, frutas, queso, huevos y otros productos. Entre semana acuden al centro poblado más cercano en busca de algún producto de la canasta familiar, para asistir a reuniones de la Junta de Acción Comunal, de Padres de Familia, a recibir talleres de capacitación, etc., y van a Florencia a realizar transacciones bancarias, actividades administrativas o asistir a eventos deportivos, culturales o recreativos.

\subsubsection{Unidad Florencia - Villa Hermosa - Bajo San Gil}

Esta unidad se extiende por la parte occidental del municipio, cubriendo una pequeña en el paisaje de montaña 
baja. Aquí se encuentran dos centros poblados pequeños (centros rurales básicos), Bajo San Gil y Villa Hermosa, los cuales dinamizan la unidad en este sector por constituir puntas de la red vial municipal. Bajo San Gil, ubicado a orillas del río Bodoquero (este río sirve de límite natural entre Florencia y Morelia) recibe toda la producción de plátano, yuca y maíz proveniente de la cuenca alta del río Bodoquero, para de allí transportarlo a los mercados de la ciudad de Florencia por la única vía de acceso que presta servicio, tanto a los habitantes de Florencia como a los de Morelia, ubicados en esta vertiente. Esta vía es destapada en toda su longitud de 11,8 km hasta conectarse con la Marginal de la Selva en el sitio conocido como Tres Esquinas, distante $13 \mathrm{~km}$ de Florencia.

Villa Hermosa, por su parte, es centro de acopio de la producción proveniente de la cordillera en territorio de Florencia. Este núcleo rural se comunica con Florencia por un carreteable de $15,1 \mathrm{~km}$ que también se conecta con la Marginal de la Selva a $5 \mathrm{~km}$ de Florencia.

Estos dos centros poblados, a su vez ofrecen algunos servicios básicos a la población rural de las siguientes veredas: El Diamante, Barcelona, El Terminal, El Jardín, Turbay,
Resguardo Honduras, Los Andes, Campo Hermoso.

\subsubsection{Unidad Villaraz - Avenida El Caraño - Florencia}

La unidad se localiza al norte del municipio en área montañosa, es atravesada de sur a norte por las vías nacionales Florencia-Guadalupe ${ }^{26}$ y Florencia-Suaza ${ }^{27}$ y a partir de la cota $1000 \mathrm{msnm}$, hace parte de la Reserva Forestal de la Amazonia, intervenida hasta los $1600 \mathrm{msnm}$, aproximadamente, límite septentrional de esta unidad.

Pertenecen a esta unidad las veredas Tarqui, Sucre, Santa Elena, Alto Paraíso, Paraíso, El Caraño, El Horizonte, Villaraz, La Paz, Avenida El Caraño, Santo Ángel, Las Doradas, Quindío, Palmichal, El Convenio.

Contiene dos centros polarizadores, a nivel rural, Villaraz y Avenida El Caraño. Estos pequeños centros ofrecen servicios a nivel veredal, son sitios de encuentro de la población que cada fin de semana se desplaza a la ciudad de Florencia, aprovechando las vías de comunicación nacional, y los sábados y domingos tienen afluencia de turistas y bañistas procedentes de Florencia, quienes aprovechan la gran oferta hídrica de los ríos Hacha y Caraño y de la quebrada Las Doradas que recorren

$\overline{26}$ Vía antigua todavía en servicio a partir del centro poblado Avenida El Caraño.

27 Vía nueva en construcción, dentro de poco reemplazará la vía antigua Florencia-Guadalupe. El tramo Florencia-Primer túnel, está en servicio. 
la unidad. Por esta razón, los centros poblados están desarrollando una pequeña infraestructura turística, representada por restaurantes, bares y adecuación de los bañaderos.

También, en esta unidad se encuentra parte de la infraestructura de la acueducto de Florencia (bocatoma, tanques desarenadores y redes de conducción), motivo por el cual un gran sector de su territorio pertenece a la zona de protección ambiental del acueducto.

Presenta de fuerte a moderada dependencia de Florencia, centro subregional que centraliza las funciones económicas, sociales, culturales, políticas y administrativas de carácter más especializadas, en todo el municipio y departamento.

\subsubsection{Unidad Venecia- Puerto Arango - Florencia}

Se encuentra ubicada hacia la parte suroriental del municipio y tiene dos centros poblados: Puerto Arango y Venecia, los cuales centralizan algunos servicios que ofertan a sus habitantes y a los de las veredas circunvecinas. Ambos centros se emplazan sobre la carretera Marginal de la Selva que de Florencia conduce a San Vicente del Caguán, pasando primero por las cabeceras municipales de La Montañita, El Paujil, El Doncello y Puerto Rico.

Venecia, aledaña al Batallón de Ingenieros Militares Liborio Mejía atiende un gran contingente de soldados que permanece en el caserío diariamente. Puerto Arango, constituye la puerta del municipio de Florencia hacia el sur del Caquetá y de la Amazonia. A través del río Orteguaza, afluente del Caquetá, se realiza todo el tráfico fluvial hacia la planicie amazónica, incluyendo los departamentos de Putumayo y Amazonas.

La actividad predominante de los habitantes rurales de esta unidad es la ganadería de doble propósito; algunos campesinos y habitantes de Florencia, subsisten de la pesca en el río Orteguaza. En el sector de Puerto Arango, se explotan dos canteras que proporcionan materiales de construcción como arena, grava y gravilla, para la ciudad de Florencia.

En el sur de la unidad se encuentra el Batallón Aerotransportado Guepí en el sitio denominado Larandia, antigua sede de los propietarios de la gran Hacienda Larandia y puerto sobre el río Orteguaza. Los habitantes de este sector, se trasladan a Florencia utilizando varias rutas, por la vía Larandia-La Ye-Puerto ArangoFlorencia; por la vía a San MartínFlorencia, o por la vía fluvial hasta Puerto Arango-Florencia.

La Universidad de la Amazonia tiene al sur de Larandia, la Granja Experimental "Balcanes" donde desarrolla proyectos agroforestales, de manejo de fauna silvestre y silvicultura. Las

96 Hugo Hernando Rincón López 
veredas que pertenecen a esta unidad son las siguientes: La Astilla, El Vergel, El Gallo, Venecia, Alto Venecia, Puerto Arango, San José de Canelos, Alto Canelos, Canelos, Casa Blanca, Germania, Balcanes, Larandia, La Esperanza y las parcelas de desmovilizados del M19, La Libertad, La Paz y La Independencia.

\subsubsection{Unidad Remolino Orteguaza -} La Esperanza - Santana Las Hermo- sas - San Antonio de Atenas - Florencia

Localizada en el centro-oriente del municipio a lo largo del río Orteguaza en el paisaje de montaña; contiene cuatro centros poblados (Remolino Orteguaza, La Esperanza, Santana las Hermosas y San Antonio de Atenas) interconectados por una vía carreteable que se desprende de la carretera Marginal de la Selva en dirección norte, penetrando en la cordillera Oriental por el valle del río Orteguaza (margen derecha) hasta el sitio denominado Año Nuevo. Remolino, ubicado más al norte, se comunica a través de un camino que conduce a la Esperanza y de ahí se interconecta con Florencia por medio de transporte público.

En esta zona predomina la ganadería extensiva de doble propósito y se cultiva plátano, café y algunos frutales. La Educación secundaria es atendida por el
Colegio de Santana Las Hermosas, caserío ubicado en un punto intermedio entre La Esperanza y San Antonio de Atenas, cabecera del Corregimiento Orteguaza. Los cuatro centros poblados tienen energía eléctrica por el sistema de interconexión con la Florencia y ofrecen servicios básicos a sus pobladores y a los habitantes rurales de sus áreas de influencia, pertenecientes a las veredas: El Ural, Alejandría, Ramos, Las Torres, Año Nuevo, Alto Palmar, La Ilusión, Villanueva, El Cedro, Sinaí Bajo, Cristalina, La Nueva Paz, Miraflores, San Francisco, Agua Linda, El Chontaduro, Las Hermosas, Argelia, Irlanda, La Paila, El Hoyo, El Roble, El Reflejo, San Cristóbal Alto y San Cristóbal Bajo.

\subsubsection{Unidad El Pará - Norcasia - Maracaibo - Florencia}

Esta unidad se localiza en el extremo oriental del municipio en límites con La Montañita; su configuración espacial está dada por el río San Pedro y el eje vial que recorre la zona de sur a norte por el costado derecho del río y que le sirve como eje integrador con la ciudad de Florencia.

Sus tres centros poblados (El Pará, Norcasia y Maracaibo) dinamizan el desarrollo de esta unidad muy rica en ganadería de doble propósito. En las vegas del río San Pedro existen grandes haciendas con pastos 
manejados y ganado mejorado genéticamente y en las vertientes altas de la cordillera se cultiva café, lulo, curuba y otros productos agrícolas. Norcasia ofrece educación secundaria y media a la población estudiantil de la zona, es cabecera del Corregimiento del San Pedro y dispone de una cooperativa agraria. El SENA tiene un centro de formación y experimentación en el Pará y toda la unidad tiene interconexión eléctrica, servicio de TELECOM y servicios públicos básicos.

Las veredas que conforman esta unidad son las siguientes: Tovar Zambrano, San Lorenzo, La Florida, San José Alta San Pedro, La Estrella, Palmarito, río Bravo, Buenos Aires, San Pablo, El Rosal, Begonia, Sinaí, Vista Hermosa, Dos Valles, Manzanares, Calamar, El Pielroja, Alta Victoria, La Victoria Baja y La Primavera.

Las veredas más septentrionales, tales como Tovar Zambrano, San Lorenzo, La Florida, San José Alta San Pedro y La Estrella, se encuentran dentro de la Reserva Forestal de la Amazonia, razón que ha impedido la adjudicación de los predios a los colonos.

El transporte público es ofrecido por las empresas Coomotor Florencia y Cootranscaquetá, las cuales tienen rutas diarias a través de "chivas" (vehículos mixtos para pasajeros y carga) que hacen el recorrido, pasando por cada uno de los centros poblados.

\subsubsection{Unidad San Guillermo - Garzón}

Unidad ubicada en el extremo norte del municipio en límites con el departamento del Huila. Esta zona en su totalidad se encuentra dentro de la Reserva Forestal de la Amazonia, lugar de nacimiento de varios afluentes del río Orteguaza y presenta alta fragilidad ambiental, según los estudios realizados en el marco del POT municipal.

El área intervenida cubre el centro poblado de San Guillermo y las veredas El Quebradón, Los Alpes, Turín, El Carmen y Villa Hermosa, los cuales están completamente desintegrados de la ciudad de Florencia, teniendo como centro polarizador la ciudad de Garzón en el Huila, vínculo que se estable a través de un carreteable en mal estado que va de San Guillermo a esa ciudad. Para desplazarse a Florencia, los habitantes tienen que llegar a Garzón y de ahí, esperar las rutas nacionales procedentes de Neiva, Bogotá, Armenia, Pereira u otra ciudad de interior, hacia Florencia, en este recorrido se invierte un día completo.

San Guillermo, en calidad de centro rural secundario brinda algunos servicios a la comunidad de las veredas de la zona y para ello cuenta con escuela, puesto de salud, matadero, tiendas misceláneas, salón comunal, cooperativas y otros servicios elementales. 


\subsection{8 Área No Polarizada}

El área no polarizada corresponde a la Reserva Forestal de la Amazonia que se encuentra sin intervenir y se localiza en la cordillera Oriental, en la parte norte del municipio, formando una franja transversal de oeste a este a partir de la cota $1000 \mathrm{msnm}$ en algunos sectores y en otros, esta cota ya ha sido rebasada por los colonos que han intervenido la Reserva sin que los detenga esta restricción.

Esta unidad presenta bosques de niebla subandinos y andinos, con alta diversidad biológica y endemismo, y en ella tienen lugar el nacimiento de varios ríos y afluentes importantes, tales como el río Bodoquero, el Batato, El Caraño, el Hacha, el Orteguaza y el San Pedro y quebradas como las Doradas, La Perdiz y otras de gran caudal. Dentro del Plan de Ordenamiento Territorial del municipio de Florencia, esta zona está catalogada como un ecosistema estratégico de alta fragilidad ambiental que es necesario proteger para conservar su flora y fauna y garantizar los bienes y servicios ambientales que presta al municipio.
Esta zona de preservación estricta está atravesada de sur a norte por las vías nacionales que comunican a Florencia y al departamento con el interior del país: carretera FlorenciaGuadalupe (vía antigua, todavía en funcionamiento) y carretera Florencia-Suaza (vía nueva en funcionamiento parcial). El trazo del eje vial antiguo, es paralelo al río Hacha por su orilla izquierda hasta su nacimiento y el nuevo, va paralelo a este río por la orilla derecha hasta el centro poblado Avenida El Caraño, donde se desvía hacia el oeste para seguir el recorrido del río Caraño hasta la depresión El Vergel (límite con el departamento del Huila). Estos dos ejes viales, han promovido el avance de la colonización y penetración a la Reserva Forestal, sin que las autoridades ambientales hayan podido impedir estos asentamientos.

Igual sucedió con las carreteras municipales que van hacia La Esperanza con proyección a Remolino Orteguaza y San Guillermo, y la que finaliza en El Pará, las cuales facilitaron la penetración de colonos hacia la Reserva, presionando su intervención. 


\section{Bibliografía}

ALCALDÍA MUNICIPAL DE FLORENCIA. Plan de ordenamiento territorial: documento técnico de soporte. Santafé de Bogotá : FONADE, 2000.

Canto Fresno, Consuelo del. Trabajos prácticos de geografía humana. Madrid : Editorial Síntesis, 1993.

COLOMBIA. CONGRESO DE LA REPÚBLICA. Ley 136 de 1994.

Ley 388 de 1997.

Canto Fresno, Consuelo del. Trabajos prácticos de geografía. Madrid : Editorial Síntesis, 1993.

DEPARTAMENTO ADMINISTRATIVO NACIONAL DE ESTADÍSTICA - DANE. Censos de población y vivienda de 1973, 1985, 1993 y proyecciones de población.

Estebanez, José y Bradshaw, Roy. Técnicas de cuantificación en geografía. Madrid: Tebas Flores, 1982.

Godoy G., Rubén D. Proceso de ocupación y variación espacial de la población en el Caquetá y Putumayo, 1850-1994. Santafé de Bogotá, 1995. Tesis (Magister en Geografía). Universidad Pedagógica y Tecnológica de Colombia/Instituto Geográfico Agustín Codazzi. Escuela de Postgrado en Geografía.

Gutiérrez Puebla, Javier. La ciudad y la organización regional. Santafé de Bogotá: Editorial Cincel, 1992. (Cuadernos de estudio. Serie geografía; No. 14).

Gutiérrez Rey, Franz J. A. La organización e integración funcional del sistema urbano en el departamento de Caquetá. Santafé de Bogotá: Instituto SINCHI, 1999.

____- y Arcila, Oscar. Sistema urbano. En: INSTITUTO AMAZÓNICO DE INVESTIGACIONES CIENTÍFICAS. Caquetá: dinámica de un proceso. Santafé de Bogotá: Instituto SINCHI, 2000b. P. 55-73.

INSTITUTO GEOGRÁFICO AGUSTÍN CODAZZI (IGAC). Subsistema de funcionamiento espacial: aplicación metodológica al ordenamiento territorial. Santafé de Bogotá : IGAC, 2000. p. 31 (Versión CD ROM).

Bases conceptuales y guía metodológica para la planificación y el ordenamiento territorial departamental. Santafé de Bogotá: IGAC, 1997.

Guía metodológica para la formulación del plan de ordenamiento territorial municipal. Santafé de Bogotá : IGAC, 1997.

- Guía metodológica para la formulación del plan de ordenamiento territorial urbano: aplicable a ciudades. Santafé de Bogotá: IGAC, 1996.

___ Aspectos ambientales para el ordenamiento territorial del occidente del departamento del Caquetá. Santafé de Bogotá: IGAC/INPA1, 1993. (Estudios en la Amazonia Colombiana, VIA).

Racionero, Luis. Sistemas de ciudades y ordenación del territorio. Madrid: Alianza Editorial, 1981.

Rondinelli, Dennis A. Método aplicado de análisis regional: la dimensión espacial de la política de desarrollo. Santafé de Bogotá: Gobernación de Antioquia/Banco Central hipotecario, 1988.

TERMINAL DE TRANSPORTES DE FLORENCIA. Movimiento operativo de automotores (Base de datos año 2000).

100 Hugo Hernando Rincón López 